\title{
Reviews
}

\section{Evolutionary aspects of oncogenic herpesviruses}

\author{
J Nicholas
}

\begin{abstract}
Several of the $\gamma$-herpesviruses are known to have cellular transforming and oncogenic properties. The genomes of eight distinct $\gamma$-herpesviruses have been sequenced, and the resulting database of information has enabled the identification of genetic similarities and differences between evolutionarily closely related and distant viruses of the subfamily and between the $\gamma$-herpesviruses and other members of the herpesvirus family. The recognition of coincident loci of genetic divergence between individual $\gamma$-herpesviruses and the identification of novel genes and cellular gene homologues in these genomic regions has delineated a subset of genes that are likely to contribute to the unique biological properties of these viruses. These genes, together with $\gamma$-herpesvirus conserved genes not found in viruses outside the family, might be responsible for virus specific pathogenicity and pathogenic effects, such as viral associated neoplasia, characteristic of the subfamily. The presence of the $\gamma$-herpesvirus major divergent genomic loci and the apparent increased mutational frequencies of homologous genes (where they occur) within these regions, indicates that these loci possess particular features that drive genetic divergence. Whatever the mechanisms underlying this phenomenon, it potentially provides the basis for the relatively rapid adaptation and evolution of $\gamma$-herpesviruses and the diversity of biological and pathogenic properties. (f Clin Pathol: Mol Pathol 2000;53:222-237)
\end{abstract}

Keywords: $\gamma$-herpesviruses; evolution; oncogenes

Molecular Virology Laboratories, Department of Oncology, John Hopkins University School of Medicine, Baltimore, Maryland 21231, USA

Correspondence to: Dr Nicholas nichojo@ mail.jhmi.edu

Accepted for publication 23 May 2000 hypotheses concerning the evolution of individual herpesvirus species from a presumed single ancestral genome, and to assess the relative importance and functions of particular genes (acquired from host cells in the recent or distant past) with respect to viral biology and pathogenesis. This review will begin by overviewing the organisation and other aspects of $\gamma$-herpesvirus genomes, including their relations to other members of the herpesvirus family (the $\alpha$-herpesviruses and $\beta$-herpesviruses), and mechanisms of genomic variation, and then move on to discussions of $\gamma$-herpesvirus divergent genomic loci and the features and potential biological importance of some of the genes encoded by these regions. Breadth of scope and generality of ideas, rather than detailed genetic analyses and comprehensive reviews of gene function, is the aim. Excellent original papers and reviews that deal in depth with specific aspects of herpesvirus genetic analysis, evolutionary origins, and gene function have been published previously. These provide the basis for this chapter and are cited herein.

\section{Herpesvirus subfamilies and genome organisation}

The classification of herpesviruses into three major subgroups ( $\alpha, \beta$, and $\gamma$ ) was based initially on patterns of in vivo and in vitro biological properties. These included tissue and host specificity of latent and productive infection in vivo, host cell range in tissue culture, and the duration and other characteristics of in vitro productive infection. With respect to the latent tropisms of herpesviruses, the $\alpha$-herpesviruses are neurotropic and include herpes simplex viruses types 1 and 2 (HSV-1 and HSV-2), and varicella zoster virus (VZV); the $\gamma$-herpesviruses are lymphotropic and include Epstein-Barr virus (EBV), human herpesvirus 8 (HHV-8), herpesvirus saimiri (HVS), and murine herpesvirus 68 (MHV-68). The predominant cellular sites of latency of the $\beta$-herpesviruses - for example, human cytomegalovirus (HCMV) and human herpesviruses 6 and 7 (HHV-6 and HHV-7) - have not been defined.

It has become clear from the results of large scale sequence analyses of herpesvirus genomes that the biological subgroup assignments, as applied to herpesviruses of avian and mammalian hosts, can be correlated with the genetic content, gene organisation, and degree of conservation of homologous herpesvirus genes, as well as with certain non-coding features (such as the conservation of specific 
types of terminal or internal repetitive elements and deviations in observed versus expected dinucleotide frequencies (see below)) of the viral genomes. Within all characterised herpesvirus genomes there are conserved genes, representing each kinetic class (immediateearly, early, late), which comprise $25-70 \%$ of the genes within a particular virus. Many of these conserved "core" genes are clustered together and can be recognised as "gene blocks" within different herpesvirus genomes. ${ }^{1}$ The herpesvirus conserved genes within members of a herpesvirus subgroup appear in equivalent locations within appropriately aligned genomes, and in the same relative orientations. ${ }^{1-9}$ In general, these genes are better conserved between members of the same subgroup than they are between subgroups. The derivation of phylogenetic trees through the analysis of degrees of relatedness of these genes has provided strong evidence that herpesviruses have coevolved with their hosts. ${ }^{10}$ Members of the same herpesvirus subfamily possess genes common and specific to the subgroup, and these genes, comprising $15-25 \%$ of the total genome content, are (in almost all cases) positionally conserved. In addition to the core and subfamily specific genes, each herpesvirus contains unique or partially conserved genes, the "virus specific" genes. These genes may include recognisable cellular gene homologues that have been acquired evolutionarily recently or ancient genes that have since been lost by many or most members of the subgroup. Evidence for the former would be a distribution of genes within a single herpesvirus subfamily reflecting the evolutionary relations among the hosts (for example, HHV- 8 and rhesus rhadinovirus (RRV) interleukin 6 (IL-6) and interferon (IFN) regulatory factor (IRF) homologues are found only in these two $\gamma$-herpesviruses); conversely, evidence for gene loss leading to the presence of genes in only certain members of the subfamily would not lead to gene distributions among subfamily members that reflect the evolutionary relations of the host (for example, highly diverged bovine herpesvirus 4 (BHV-4) zinc finger protein (IE1) homologues are present only in HVS, HHV-8, and MHV-68). The virus specific genes might be particularly important contributors to distinctive, and potentially pathogenically important, biological properties of the viruses, but this is more likely to be true of recently acquired genes (the former category, above) than those genes whose counterparts have been lost from related viruses during the evolution of the subfamily.

\section{Mechanisms of herpesvirus genomic variation}

It is notable that herpesvirus cellular gene homologues generally do not contain introns. For example, the HVS, HHV-8, and RRV dihydrofolate reductase (DHFR) genes comprise single open reading frames (ORFs). The human DHFR gene contains five introns and spans $30 \mathrm{~kb}$ of DNA. ${ }^{11}$ Similarly, members of the immunoglobulin gene family contain numerous introns, whereas the Thy-1 homo- logues in HCMV, HHV-6, and HHV-7 comprise uninterrupted coding sequences. This suggests that the acquisition by herpesviruses of at least some cellular "genes" occurs through mRNA intermediates (lacking introns). However, there are examples of herpesvirus cellular gene homologues that have introns that are positionally (but not structurally) conserved relative to their endogenous counterparts, suggesting that they were derived either from cellular DNA or unprocessed RNA. These include a type-C lectin homologue found in rat cytomegalovirus (RCMV) (WH Burns, 2000, personal communication), the IL-10 genes of primate CMVs, ${ }^{12}$ and the U12 and UL33 G protein coupled receptor (GCR) genes encoded by $\beta_{2}$ (HHV- 6 and HHV-7) and $\beta_{1}$ (HCMV and murine CMV (MCMV)) herpesviruses, respectively. ${ }^{13}$ Conversion of mRNA (or unprocessed RNA) to DNA could involve the action of reverse transcriptase supplied by a coinfecting retrovirus. Evidence of such coinfection comes from the discovery of integrated reticuloendotheliosis virus (REV) and avian leukosis virus (ALV) sequences in the DNA of Marek's disease virus (MDV). ${ }^{14} 15$ This also demonstrates that viral as well as cellular sequences can be acquired by herpesvirus genomes. The first reported example of this was the identification of a homologue of the adeno associated virus type 2 (AAV-2) rep gene in the HHV-6 genome, thus providing evidence of direct virus-virus gene transfer (from parvovirus to herpesvirus). ${ }^{16}$ The presence in HHV-6, HHV-7, equine herpesvirus 2 (EHV2 ), and MDV terminal repeat units of reiterated sequences comprising perfect and imperfect copies of the sequence GGGTTA, corresponding to the telomeric repeat elements at the chromosome termini, indicates either that these sequences have been incorporated into the herpesvirus genomes through recombination events, or that the cellular telomerase has somehow used the viral DNA as a substrate for the addition of telomeric sequences. ${ }^{17-20}$ The observed distribution of single copies of TAACCC and complementary GGGTTA sequences within the HHV- $6 \mathrm{U}_{\mathrm{L}}$ region to the left and right, respectively, of the replication origin suggests another model for sequence insertion, namely that an RNA molecule with the TAACCC sequences is involved in the generation of Okazaki fragments on the lagging strand during DNA synthesis. ${ }^{121}$

In addition to the acquisition of heterologous sequences by herpesviruses, there is also evidence for the duplication of genes or sequence elements and gene loss. Evidence for the former includes the identification of reiterated homologous genes, exemplified by the gene families in HCMV, such as US12, US22, and RL11.22 These occur mainly as tandemly repeated genes, although family members can be dispersed. Examples of apparent gene amplification are also found among the $\gamma$-herpesviruses, where there are two or more copies of $\mathrm{N}$-formylglycinamide (FGARAT), GCR, IRF, chemokine, and IE1 genes in particular genomes (fig 1). ${ }^{2723-28}$ In addition, EBV, HVS, MHV-68, and herpesvirus ateles 
(HVA) contain tandemly reiterated copies of DNA polymerase III transcribed genes (EBV early RNAs (EBERs), uRNAs, tRNAs, and
uRNAs, respectively). Non-coding repetitive elements are present in every herpesvirus genome investigated. Most striking are the

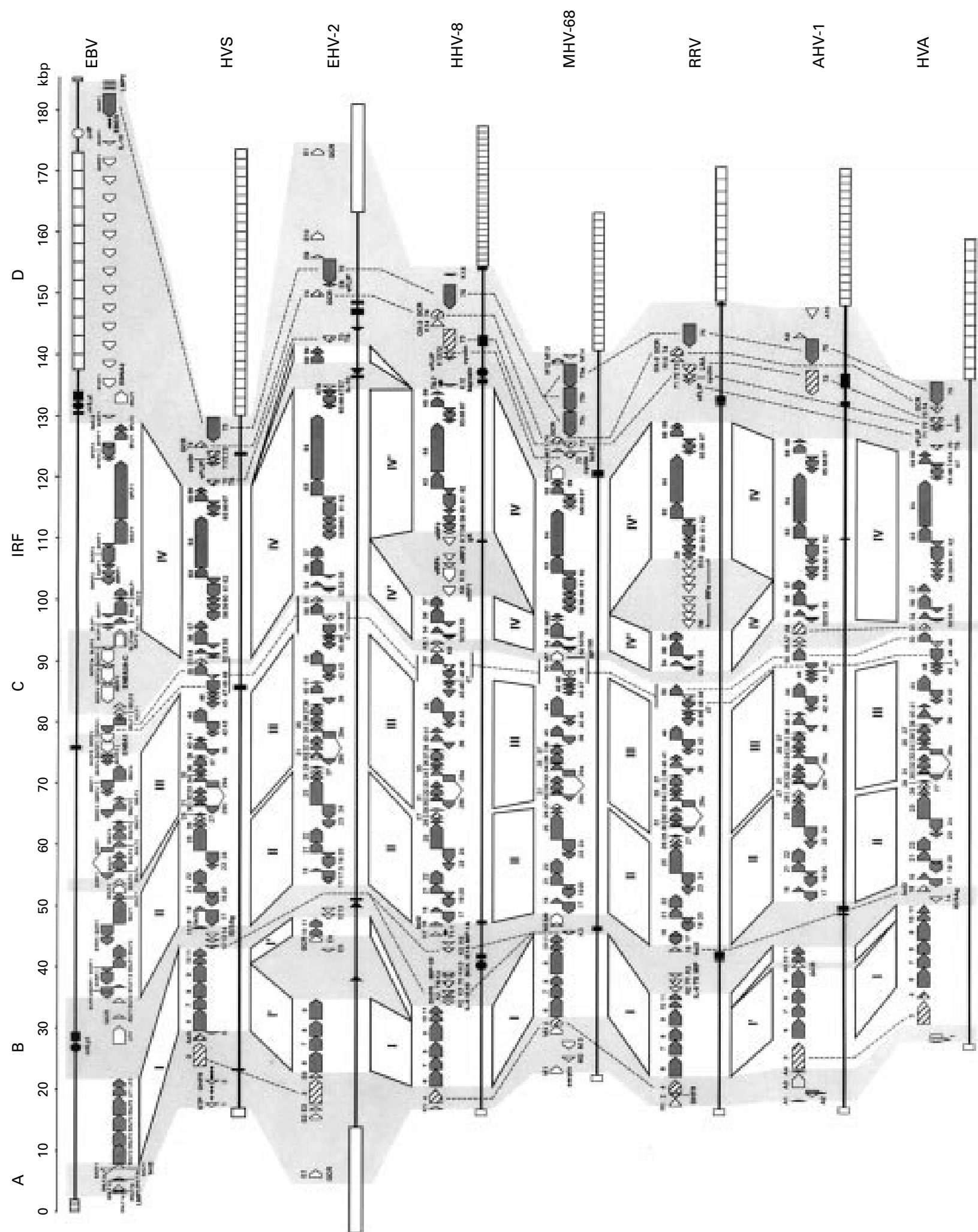

Figure 1 Alignment of the genomes of the sequenced $\gamma$-herpesviruses. Conserved homologous genes, non-conserved genes, and "unique" (shared by no more than two viruses) genes are indicated by shaded, hatched, and open arrows, respectively. Conserved gene blocks are shown by the boxes labelled I to IV, with intervening and flanking $\gamma$-herpesvirus divergent loci $(\gamma D L-A$ to $\gamma D L-D)$, divergent between multiple $\gamma$-herpesviruses, indicated by shading. Where possible, the homologous genes within the DL regions are adjoined by broken lines. The interferon regulatory factor (IRF) loci, found only in HHV-8 and RRV, disrupt conserved gene block IV. Terminal repeats, internal repeats and known or suspected replication origins are indicated by open boxes, filled boxes (or arrows), and circles, respectively. ${ }^{2}{ }_{23-26}^{28-31}$ AHV-1, alcelaphine herpesvirus 1; EBV, Epstein-Barr virus; EHV-2, equine herpesvirus 2; HHV-8, human herpesvirus 8; HVA, herpesvirus ateles; HVS, herpesvirus saimiri; MHV-68, murine herpesvirus 68; RRV, rhesus rhadinovirus. 
multiply reiterated terminal repeat elements that are typical of the $\gamma_{2}$ herpesviruses (with the exception of EHV-2; indeed, it has been proposed that EHV-2 might represent a distinct group of $\gamma$-herpesviruses because of its direct terminal repeats ${ }^{7}$ ), that together comprise up to $30 \%$ of the genome size. No transcripts have been detected from these sequences, and one hypothesis is that they function merely to provide the correct genome length for appropriate DNA packaging and cleavage during virus assembly. One can further hypothesise that the successive loss of coding sequences from the unique component of the genome during evolution has been compensated for by the amplification of repetitive sequences at the genome termini.

Evidence of gene loss is provided by the presence of a crucially important replication gene, that encoding the origin binding protein (OBP), only in the $\alpha$-herpesviruses (HSV-1, VZV, EHV-1, and EHV-4) and in the $\beta_{2}$ herpesviruses (HHV-6 and HHV-7). ${ }^{5}{ }^{82-34}$ The simplest explanation for the presence of OBP in just two of the (sequenced) $\beta$-herpesviruses (HHV-6 and HHV-7) in addition to members of the $\alpha$-herpesvirus subgroup is that the OBP gene was present in the ancestral herpesvirus genome that gave rise to the $\alpha$ and $\beta$ lineages, and that the gene has since been lost from other $\beta$-herpesviruses. These other viruses have evolved different replication initiation strategies and have distinct origins of replication. ${ }^{32}{ }^{35-38}$ An example of probable gene loss from the $\gamma_{2}$ lineage is the IE1 gene of BHV-4 (a bovine herpesvirus) that has homologues in HVS (squirrel monkey), HHV-8 (human), and MHV-68 (mouse) but not in HVA (spider monkey), RRV (rhesus macaque), EHV-2 (horse), or alcelaphine herpesvirus 1 (AHV-1; wilderbeest). Similarly, the presence of IL-8 receptor (IL-8R) related GCR homologues in the $\gamma-2$ herpesviruses HVS, EHV-2, HHV-8, RRV, and HVA, but not in the closely related $\gamma_{2}$ herpesviruses MHV-68 and AHV-1 (fig 1 ; table 1) indicates the loss of IL-8R homologues from the MHV-68 and AHV-1 genomes.

CpG suppression in the $\gamma$-herpesviruses One notable non-coding feature of most sequenced $\gamma$-herpesvirus genomes is that they have a lower frequency of $\mathrm{CpG}$ dinucleotides than would be expected from the mononucleotide composition of the genomes. Corresponding increases in $\mathrm{TpG}$ and $\mathrm{CpA}$ dinucleotide frequencies above those expected are consistent with the hypothesis that these non-random dinucleotide frequencies result from the methylation/deamination of $\mathrm{C}$ nucleotides (to give $\mathrm{T}$ ), leading to the depletion of $\mathrm{CpG}$ and an excess of $\mathrm{TpG}$ (and the complement $\mathrm{CpA}$ ). ${ }^{39}$ Thus, CpG suppression has been taken as an indication that viral genomes displaying this feature persist in a latent state in a dividing cell, and that the viral DNA is accessible to the action of cellular methylases. However, evolutionary drift of dinucleotide frequencies resulting from differences in nucleotide stacking energies has also been proposed, ${ }^{40}$ although it is unclear why, on this basis, members of the $\gamma$-herpesviruses should be unique among large DNA viruses in their susceptibility to select against thermodynamically stable $\mathrm{CpG}$ dinucleotides. HHV-8 and RRV are notably distinct from the previously sequenced $\gamma$-herpesviruses in that $\mathrm{CpG}, \mathrm{TpG}$, and $\mathrm{CpA}$ frequencies do not deviated substantially from those expected from the GC content of the viral DNA. ${ }^{24-26}$ This could indicate that the latent states of HHV-8 and RRV are fundamentally distinct from those of other characterised members of the subfamily, and that the viral genomes representing the reservoir vis a vis propagation persist in a non-dividing or methylase deficient cell type, or are somehow masked from the action of cellular methylases (assuming methylation/deamination to be the cause of $\mathrm{CpG}$ suppression). The latter scenario might apply to the $\beta$-herpesviruses, which show local depletion of $\mathrm{CpG}$ dinucleotides within only the major immediate-early loci, ${ }^{34} 39{ }^{41-43}$ presumably reflecting restricted accessibility of methylases to regions outside these loci. Although the underlying reason for the absence of $\mathrm{CpG}$ suppression in HHV-8 and RRV is unknown at present, it is tempting to speculate that this reflects biological properties, related to latency, that are common and specific to these and closely related $\gamma_{2}$ herpesviruses. Consistent with this idea is that sequences published for retroperitoneal fibromatosis virus (RPFV) strains, derived from different macaque species and thought to be evolutionarily closely related to HHV-8 and RRV, also show essentially random frequencies of $\mathrm{CpG}, \mathrm{TpG}$, and $\mathrm{CpA}$ dinucleotides. ${ }^{44}$

\section{$\gamma$-Herpesvirus major divergent loci}

Despite general genetic collinearity among herpesviruses within the same subfamily there are regions of appreciable genetic divergence. This is seen most notably at the genome termini, essentially outside the central core of conserved genes, but occurs also between conserved gene blocks, usually comprising a clustering of unique or partially conserved genes at analogous loci in coaligned genomes. ${ }^{12524424546}$ This is illustrated for the sequenced $\gamma$-herpesviruses in fig 1 .

Coincidence of genetic divergence at particular genomic locations suggests that these loci have features that allow more ready loss or acquisition of genetic material, or that they are more susceptible to and/or can accommodate higher rates of mutational change without adverse effects on replication efficiency. The observed coincident major divergent loci could be accounted for by the differential loss of genetic material from a common progenitor genome, acquisition of new genes from the host cell or a coinfecting virus, or by extensive mutational changes accommodated preferentially at these positions. As outlined above, there is evidence for both gene loss and gene acquisition by herpesvirus genomes, although the possible mechanisms that could lead to repeated gene insertions at a single genetic locus are uncertain. It is possible that increased recombination frequency occurs at the genome 


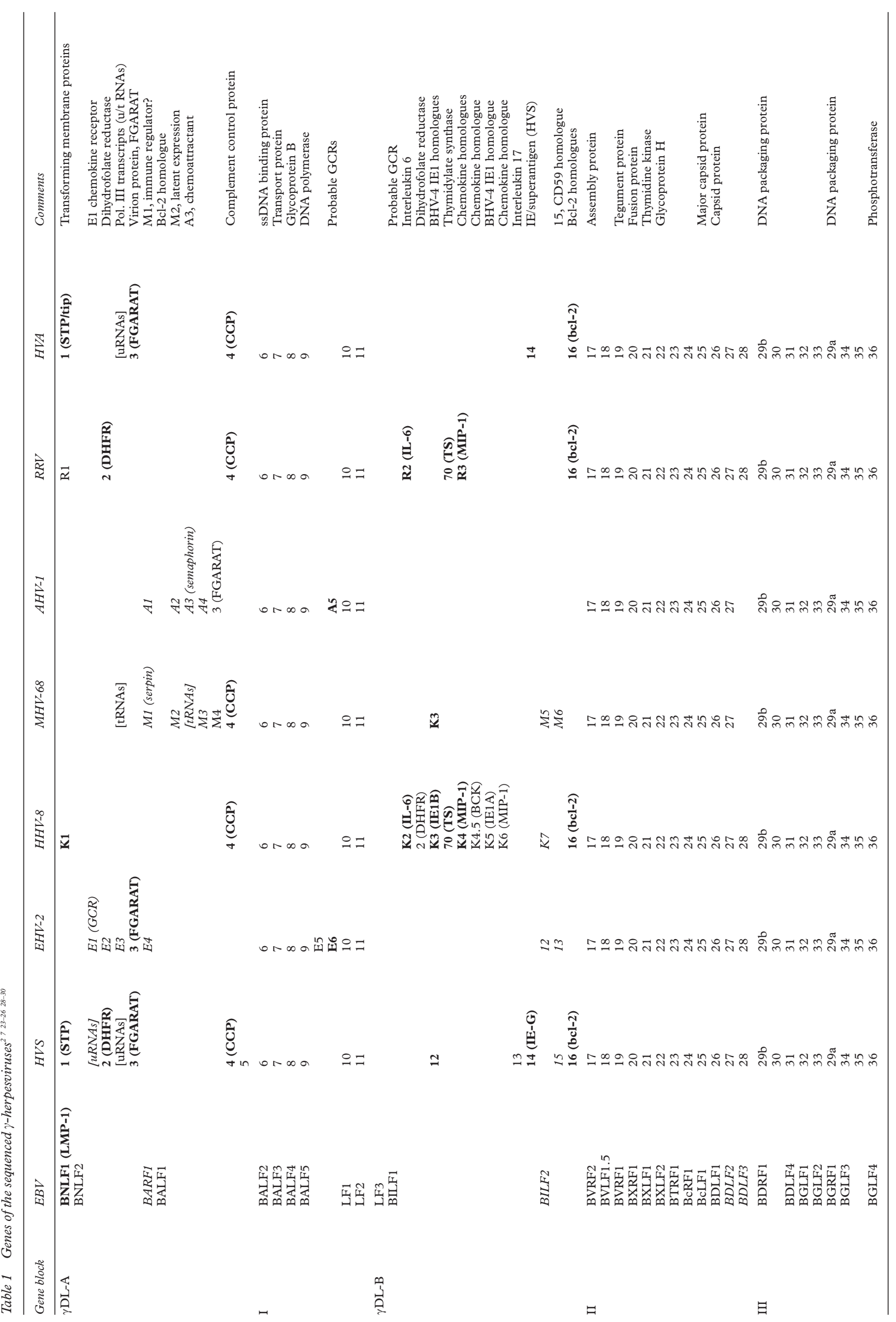

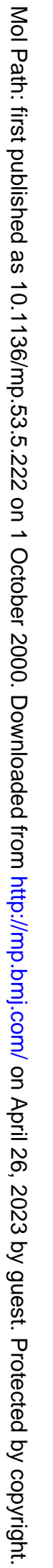




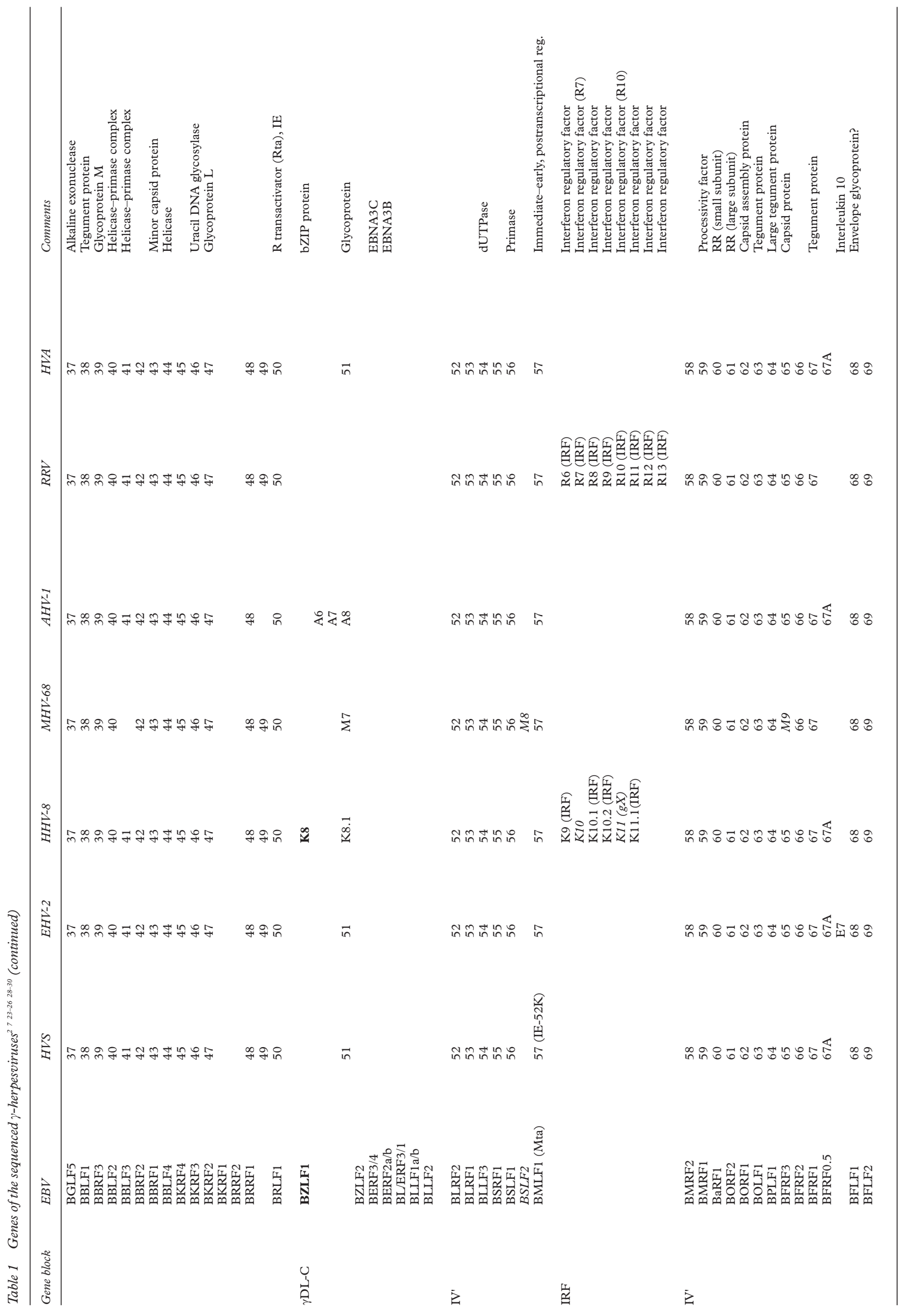




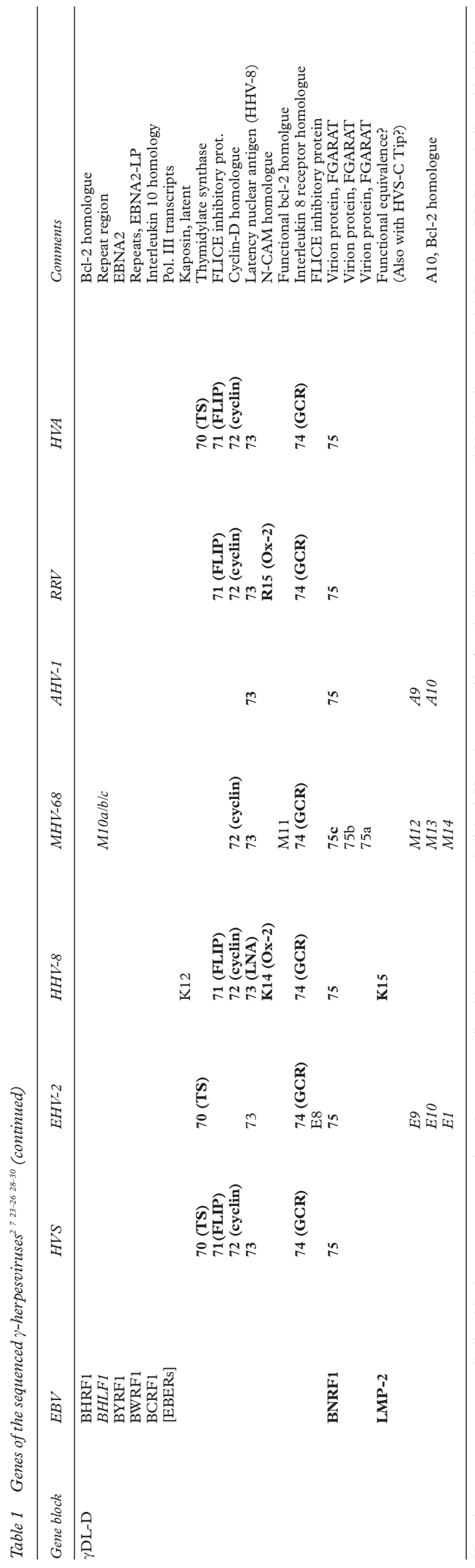

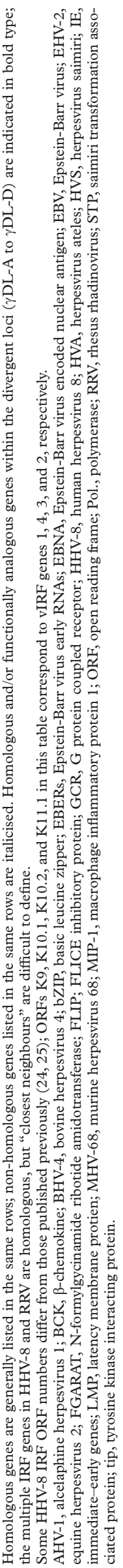

termini as a consequence of the presence of nicked and cut DNA resulting from cleavage events during packaging. Replication initiation could also be relevant to recombination events occurring within the $\gamma \mathrm{DL}-\mathrm{A}, \gamma \mathrm{DL}-\mathrm{B}$, and $\gamma$ DL-D regions, containing known or suspected latent and/or lytic replication origins. ${ }^{47-55}$ It is also possible that the presence of repetitive elements within many of the $\gamma \mathrm{DL}$ regions (fig 1) leads to genetic instability through homologous recombination, and such events would be predicted to facilitate genetic change through loss, acquisition, and duplication of sequence elements.

Genomic sequencing of multiple members of the $\gamma$-herpesviruses has allowed the identification and delineation of the major divergent loci. ${ }^{23-26}$ 28-31 46 They are referred to here as $\gamma$-herpesvirus divergent loci A to D ( $\gamma$ DL-A to $\gamma \mathrm{DL}-\mathrm{D}$; fig 1). The nomenclature is different to that used previously $y^{51}$; here, " $\gamma D L "$ refers to those loci that are divergent between multiple members of the subfamily. The genes encoded by the $\gamma$ DLs of the sequenced $\gamma$-herpesviruses are listed in table 1 along with the other genes specified by these viruses. Of particular interest is that in many of the $\gamma$-herpesviruses, genes specified by $\gamma$ DL-A and $\gamma$ DL-D sequences include those corresponding to demonstrated or putative latency genes that play roles in episomal maintenance or cellular transformation (see below). The $\gamma \mathrm{DL}-\mathrm{C}$ region of EBV also specifies latency genes, but the roles of ORFs 51 (HVS, EHV-2, and HVA), K8 and K8.1 (HHV-8), M7 (MHV-68), and A6 to A8 (AHV-1) at coincident loci in their respective $\gamma_{2}$ viral genomes remain to be determined. It is important to note, however, that $\mathrm{K} 8$ transcripts and encoded proteins show structural similarity to EBV Zta products; the Zta basic leucine zipper (bZIP) protein is involved in transcriptional activation of EBV lytic cycle genes and in lytic viral DNA replication. ${ }^{56-63}$ The $\gamma$ DL-D loci are highly divergent, but contain several common or largely conserved genes, including homologues of HHV-8 latency nuclear antigen (referred to as LNA or LANA;), ${ }^{64}{ }^{65}$ D-type cyclin, GCR, FLICE inhibitory protein (FLIP), and $\mathrm{N}$-formylglycinamide ribotide amidotransferase (FGARAT; previously referred to as $140 \mathrm{kDa}$ membrane antigen and $160 \mathrm{kDa}$ virion protein in EBV and HVS, respectively). The $\gamma \mathrm{DL}-\mathrm{B}$ locus is also highly diverged and genes within this region include the cytokines vIL-6, macrophage inflammatory protein 1 homologues vMIP-1A (vMIP-I) and vMIP-1B (vMIP-II), and the $\beta$-chemokine related BCK (vMIP-III) in HHV-8, and vIL-6 and vMIP in RRV; putative immediate-early/ regulatory genes (IE1) in HVS, HHV-8, and MHV-68; bcl-2 homologues in HVS, RRV, HHV-8, and HVA; immediate-early/ superantigen (IE/SAg) genes in HVS and HVA; GCR-like genes in EHV-2, AHV-1, and possibly EBV; and DHFR (HHV-8) and thymidylate synthase (TS) genes in HHV-8 and RRV, apparently acquired independently of homologous genes within the HVS $\gamma$ DL-A and $\gamma$ DL-D loci, as indicated by their different genomic locations and their relative degrees of 
sequence similarity to each other and their host equivalents (the viral TS translation products are no more similar to each other than to various host TS proteins and HVS DHFR is far more highly diverged from cellular DHFRs than are those of HHV-8 and RRV). ${ }^{23} 26-314566$ In addition to the diverse complement of genes found within the $\gamma \mathrm{DL}-\mathrm{B}$ loci, there is considerable divergence of homologous genes within this region (for example, the IE1, bcl-2, IL-6, and chemokine genes, where present, are highly diverged between different viruses), as is the case for homologous genes within the $\gamma$ DL-D locus (for example, vFLIP, cyclin, LNA, Ox-2, and GCR). Similarly, within $\gamma$ DL-A the HHV-8 K1 gene shows extensive divergence between strains, and the collinear "functional homologues" latent membrane protein 1 (LMP-1), saimiri transformation protein (STP), R1, and Tio in EBV, HVS, RRV, and HVA, respectively, have no or little (STP/Tio) amino acid sequence similarity. ${ }^{23}$ 67-69 Furthermore, there are three distinct STP alleles (with some A subtypes, at least, showing relatively high degrees of divergence) and two distinct K15 alleles (within $\gamma$ DL-D) among different strains of HVS and HHV-8, providing additional evidence of $\gamma$ DL-A and $\gamma$ DL-D susceptibility to genetic alteration, possibly involving interspecies recombination. ${ }^{68}{ }^{70-74}$ There is also evidence of tandem duplication and high rates of mutational change of the multiple IRF genes (presumably derived from an evolutionarily recently acquired single gene) in the "IRF locus" of HHV-8 and RRV (fig 1; table 1). Divergence of genetic content and homologous genes within the major divergent loci could reflect the location of these genes at or near replication origins, repetitive sequence elements, and/or genome termini.

Recognition of the $\gamma$-herpesvirus divergent loci, within the context of otherwise stable genomes in which the core replication and structural genes are, in general, highly conserved, is important because it indicates that the acquisition of unique genes, in addition to gene loss and extensive mutational changes, is relatively commonplace and could provide the mechanistic basis of speciation among these viruses. Thus, the acquisition of specialised functions could confer unique and biologically profound properties to the virus, effecting segregation into distinct biological niches, with high rates of mutation of $\gamma \mathrm{DL}$ genes providing the basis for fine tuning of gene function through natural selection. Selected sequencing of the $\gamma \mathrm{DLs}$ of newly discovered $\gamma$-herpesviruses can allow for the rapid discovery of new genes likely to contribute to the distinct biological and pathogenic properties of these viruses. $^{45} 75$

\section{General, $\gamma$-herpesvirus specific, and virus specific functions evaluated by genome comparisons}

The availability of complete genome sequences for eight of the $\gamma$-herpesviruses, together with sequence determinations for multiple members of the $\alpha$-herpesviruses and $\beta$-herpesviruses, allows an assessment of the generality or specificity of their functions with respect to herpesvirus biology, based on their particular distributions among herpesvirus genomes. The genes listed in table 2 have been categorised to reflect their general or specific occurrence in herpesvirus genomes, as viewed from the perspective of the $\gamma$-herpesviruses. The "core" genes listed are examples of those genes that occur in every herpesvirus and that function as "housekeeping" genes, enabling infection, replication, and assembly of the viruses. The "cross subfamily" genes are those that are present only in some herpesviruses, but are not confined to one subfamily. They might be derived from single ancestral genes (before the formation of subfamily lineages) or acquired

Table 2 General, $\gamma$-herpesvirus specific, and virus specific genes

\begin{tabular}{|c|c|c|c|}
\hline Core genes $(\alpha, \beta, \gamma)$ & $\begin{array}{l}\text { Cross subfamily } \\
\text { general }^{*} \text { specific }\end{array}$ & $\begin{array}{l}\gamma \text { General } \\
\text { (virus shared) }\end{array}$ & $\gamma$ Specialised (virus specific) \\
\hline $\operatorname{MDBP}(6)$ & $\operatorname{GCR}\left(\beta^{\mathrm{a}}, \gamma^{\mathrm{a}}\right)$ & FGARAT $(3,75)$ & STP/K1/R1/Tio/LMP1 \\
\hline Transport protein (7) & $\mathrm{Ox}-2\left(\beta^{\mathrm{b}}, \gamma^{\mathrm{b}}\right)$ & $\mathrm{CCP}^{\star}(4)\left(\gamma_{2}\right)$ & Tipt/LMP2/Tio \\
\hline Glycoprotein B (8) & $\operatorname{OBP}\left(\alpha^{\mathrm{a}}, \beta^{\mathrm{b}}\right)$ & $\mathrm{Bcl}-2^{\star \star}(16)$ & DHFR (2) (HVS, HHV-8, RRV) \\
\hline DNA polymerase (9) & Chemokines $\left(\beta^{\mathrm{b}}, \gamma^{\mathrm{b}}\right)$ & Rta (50) & IE1 (12) (HVS, HVA) \\
\hline Major capsid protein (25) & TS $\left(\alpha^{\mathrm{b}}, \gamma^{\mathrm{b}}\right)$ & FLIP (71) & IE/SAg (14) (HVS, HVA) \\
\hline Terminase (29) & & Cyclin-D* $(72)\left(\gamma_{2}\right)$ & CD59 (15) (HVS) \\
\hline Phosphotransferase (36) & & LNA (73)/EBNA1 & IL-6 (HHV-8, RRV) \\
\hline Alkaline exonuclease (37) & & EBNA2 $\left(\gamma_{1}\right)$ & Chemokines (HHV-8, RRV) \\
\hline Helicase-primase $(40,41,44,56)$ & & $\mathrm{GCR}^{\star \star \star}$ & IRFs (HHV-8, RRV) \\
\hline Uracil DNA glycosylase (46) & & & Ox-2 (HHV-8, RRV) \\
\hline dUTPase (54) & & & IL-10 (EBV, EHV-2) \\
\hline $\mathrm{M}$ transactivator (57) & & & Serpin (MHV-68) \\
\hline Processivity factor (59) & & & Semaphorin (MHV-68) \\
\hline Ribonucleotide reductase (61) & & & Pol. III RNAs $\ddagger$ (EBV, HVS, MHV-68, HVA) \\
\hline Large tegument protein (64) & & & \\
\hline
\end{tabular}

Numbers in parentheses correspond to HVS ORF designations.

The list of core genes is not comprehensive, it gives examples only.

$\star$ These genes are not present in EHV-2 or AHV-1.

$\star \star \mathrm{Bcl}-2$ homologues present in every $\gamma$ herpesvirus, but not all in same genomic locus.

$\star \star \star$ Most $\gamma-{ }_{2}$ GCRs in $\gamma$ DL-D; EBV and ungulate $\gamma_{2}$ s (EHV-2, AHV-1) have probable GCRs in $\gamma$ DL-B.

tPresent in C-strains of HVS.

$\ddagger$ Different DNA polymerase III genes (EBERs, EBV; uRNAs, HVS and HVA; tRNAs, MHV-68).

$\mathrm{CCP}$, complement control protein; DHFR, dihydrofolate reductase; EBERs, Epstein-Barr virus early RNAs; EBNA, Epstein-Barr virus encoded nuclear antigen; EBV, Epstein-Barr virus; EHV-2, equine herpesvirus 2; FGARAT, N-formylgycinamide ribotide amidotransferase; FLIP; FLICE inhibitory protein; GCR, G protein coupled receptor; HHV-8, human herpesvirus 8; HVA, herpesvirus ateles; HVS, herpesvirus saimiri; IE, immediate-early; IL, interleukin; IRF, interferon regulatory factor; LMP, latency membrane protein; LNA, latency nuclear antigen; MDBP, major DNA binding protein; MHV-68, murine herpesvirus 68; OBP, origin binding protein; ORF, open reading frame; Pol., polymerase; RRV, rhesus rhadinovirus; Rta, R transactivator; SAg, superantigen; STP, saimiri transformation associated protein; tip, tyrosine kinase interacting protein; tio, "two-in one" protein; TS, thymidylate synthase. 
independently through distinct recombination events. GCR and Ox-2 homologues present in the $\beta$-herpesviruses (equivalents of HCMV UL78 and HHV-6/HHV-7 ORFs U51 and U85) and $\gamma$-herpesviruses (equivalents of HVS gene 74 , and the K14 and R15 genes of HHV-8 and RRV) are possible examples of the former, whereas the chemokine genes of HCMV (UL146 and UL147) and MCMV (M131/ 129) are probably unrelated to those that are present in HHV-8 and RRV. ${ }^{76-78}$ These genes, whether acquired independently or derived from common ancestral viral genes, could be considered to be essentially "modulatory" in function, conferring general selective advantages, that may be genome and cell specific, rather than profoundly unique properties that might be involved in virus speciation or contribute to virus specific pathogenic properties. However, it is also possible that genes that are directly homologous but diverged, or that are distant members the same gene family (such as chemokines or GCRs), could specify functions that are fundamentally distinct vis a vis virus biology and pathogenesis. The " $\gamma$ general" genes are those that are confined to the $\gamma$-herpesviruses and that are, in general, $\gamma$-herpesvirus conserved, indicating that these genes might be important for virus replication and latency in biological niches occupied by all or most members of the subfamily. These genes include those that define general $\gamma$-herpesvirus properties. The " $\gamma$ virus specific" genes, present only in particular members of the subfamily and predicted to specify specialised functions, include IL-6 (HHV-8 and RRV), IL-10 (EBV and EHV-2), IL-17 (HVS), IRFs (HHV-8 and RRV), IE14/SAg (HVS and HVA), and CD59 (HVS). These genes are likely to be involved in various aspects of cell signalling and gene regulation (cytokines, IRFs, and IE14/SAg) and immune evasion (CD59) that are important during lytic replication and/or latency. ${ }^{24}{ }^{79-94}$ The HVS encoded superantigen homologue (specified by ORF14) provides an example of a virus specific gene that contributes directly to HVS pathogenesis; a viral ORF14 deletion mutant was found to be non-transforming in vitro and was nononcogenic and could not persist at high levels in vivo. ${ }^{82}$ The group of virus specific genes also includes those encoding the demonstrated or putative transforming latent membrane proteins LMP-1 (EBV), STP (HVS), K1 (HHV8), R1 (RRV), and Tio (HVA), and HUS-C Tip and LMP-2 that are likely to be functionally analogous (see below) and possibly homologous (evolutionarily related) despite their lack of discernable amino acid sequence similarity. As such, they might more appropriately belong in the " $\gamma$ general" category (table 2 ), but possible equivalents of these genes in EHV-2, MHV-68, and AHV-1 have not been identified. The latency membrane proteins, EBNA/LNA and other genes likely to be of special relevance to viral persistence, transformation, and pathogenesis are discussed below.

\section{Membrane proteins associated with} transformation

For at least four of the $\gamma$-herpesviruses, genes expressed during latency and/or encoding transforming functions have been identified at the left ends (HVS orientation) of the genomes. Thus in EBV, HVS, HHV-8, and RRV, collinear genes present at the left genome termini have been shown to transform cells in various in vitro and in vivo experiments. EBV, HVS, HHV-8, and RRV transforming genes encode LMP-1, STP, and the K1 and R1 membrane proteins, respectively, each of which has demonstrable immortalising functions, and some of which have been shown to effect or be necessary for virus induced transformation in vivo. ${ }^{95-102}$ LMP-1, STP, K1, and R1 do not share discernable amino acid sequence similarity, but they appear to be functionally equivalent, and are involved in the constitutive cell proliferation signalling necessary for (or likely to be involved in for $\mathrm{K} 1$ and $\mathrm{R} 1$ ) virus induced transformation. Whereas the $\gamma_{1}$ specified LMP-1 is a six transmembrane spanning protein, its positional and functional equivalents in the $\gamma_{2}$ herpesviruses are single transmembrane domain proteins. Each is able to induce cell proliferation signals, although the mechanistic basis of signal transduction is distinct for LMP-1/STP and K1/R1. LMP-1 and STP associate with tumour necrosis factor (TNF) receptor associated factors (TRAFs), with LMP-1 also associating with TNF receptor associated death domain (TRADD) protein, whereas the $\mathrm{K} 1$ and $\mathrm{R} 1$ proteins of HHV-8 and RRV contain immunoreceptor tyrosine based activation motifs (ITAMs), which interact with several cellular signalling protein tyrosine kinases, such as Vav and Syk, to effect cellular proliferation..$^{97} 100$ 103-110

In addition to STP, HVS strains C (but not strains $\mathrm{A}$ and $\mathrm{B}$ ) contain an adjacent gene encoded by a bicistronic transcript also containing the STP ORF that specifies a protein, TIP (tyrosine kinase interacting protein), which is expressed during HVS latency, at least in experimentally infected cells. ${ }^{95} 111$ TIP interacts with the $\mathrm{T}$ cell tyrosine kinase Lck to inhibit $\mathrm{T}$ cell receptor (TCR) mediated signal transduction, thereby negatively modulating the transforming activity of HVS-C viruses. ${ }^{95} 112113$ Notably, EBV LMP-2 is functionally equivalent to TIP in that it inhibits B cell activation, ${ }^{114}$ a function thought to be important in the maintenance of viral latency in lymphoblastoid cells. LMP-2 is a 12 transmembrane domain protein containing two N-terminal cytoplasmic ITAM motifs that can interact with Src family tyrosine kinases and Syk to effect intracellular signalling, ${ }^{114-117}$ although the importance of such signalling is uncertain and LMP-2 is dispensable for the EBV immortalisation of $\mathrm{B}$ cells. ${ }^{118} 119$ In HHV-8, the K15 gene encodes a 12 transmembrane domain protein containing tyrosine kinase protein binding motifs (YASIL and YEEVL). ${ }^{71} 74120$ The K15 gene product has been shown to inhibit $B$ cell receptor signalling, ${ }^{120}$ thereby displaying properties similar to LMP-2 and TIP. The collinear 
genomic positions of $\mathrm{K} 15$ and LMP-2, and their functional and splicing similarities, ${ }^{71}{ }^{74}$ indicate that they share evolutionary origins.

Importantly from an evolutionary perspective, the STP and K1 proteins are known to be highly divergent between different strains of HVS and HHV-8. ${ }^{51697273121}$ Three types of STP have been recognised, encoded by the A, $\mathrm{B}$, and $\mathrm{C}$ subtypes of $\mathrm{HVS}$, and the oncogenic potential of strains from each HVS type appears to correlate with the particular STP that they specify. ${ }^{70}{ }^{73} 122123$ The overall structures of these proteins are generally analogous, with an acidic $\mathrm{N}$-terminus and transmembrane domain followed by a region comprised of collagen-like repeats and a C-terminal hydrophobic cytoplasmic domain. In addition to intersubtype STP variation, STP proteins from different HVS-A isolates show considerable heterogeneity. ${ }^{72}$ For K1, high degrees (far in excess of expected intraspecies protein differences) of sequence variation are seen across the entire lengths of the proteins and even higher divergence within two extracellular domains, VR1 and VR2 ${ }^{68}{ }^{69}$ These variations group into at least four subtypes (A to D), likely to reflect long term evolutionary divergence of the type seen with other herpesvirus proteins, with intrasubgroup variations, largely concentrated within the VR loops, defining several clades that are likely to have arisen over a far shorter time frame. ${ }^{68}$ The latter variations in $\mathrm{K} 1$ are distinctive, in that the observed nucleotide changes within the VR coding sequences are largely non-random, with a bias in favour of amino acid changes; that is, these changes result from the positive selection of appropriately modified $\mathrm{K} 1$ proteins for reasons that might involve immune evasion, $\mathrm{K} 1$ restricted host infectibility, or $\mathrm{K} 1$ restricted host cell range. ${ }^{68}$ The fact that the positionally and functionally analogous (but not detectably similar with respect to amino acid sequence) STP and K1 proteins show pronounced variation between isolates strengthens the hypothesis that their genes might be evolutionarily related, because high rates of mutational changes over an evolutionary time scale (since the divergence of the human and simian hosts) in proportion to the more recent divergence of these proteins between different virus isolates would inevitably have led to amino acid changes so extensive as to obliterate recognisable sequence similarities.

Finally, mention should be made of the HVA and MHV-68 genes Tio ("two in one") and M2 that are specified by sequences collinear with STP/K1/R1/LMP-1. ${ }^{23}$ The Tio ORF encodes a protein that is homologous to both STP (most closely related to STP-C) and TIP (hence "Tio"). Both Tio and M2 are expressed in latently infected, transformed cells, consistent with the notion that they are (Tio) or could be (M2) analogous to their positional counterparts in HVS, HHV-8, RRV, and EBV; Tio has been shown to bind Src family kinases. ${ }^{124} 125$

\section{Nuclear latency proteins}

It has been shown that EBV $\left(\gamma_{1}\right)$ and HHV-8 $\left(\gamma_{2}\right)$ encode nuclear proteins that are expressed during latency and that play roles in episomal genome maintenance and replication and/or promoting cellular proliferation. However, the genes for these proteins are distinct in the $\gamma_{1}$ and $\gamma_{2}$ viruses, being specified by sequences corresponding to $\gamma \mathrm{DL}-\mathrm{C}$ and $\gamma \mathrm{DL}-\mathrm{D}$ in EBV and $\gamma$ DL-D in HHV-8 and other $\gamma_{2}$ genomes (fig 1). EBV nuclear antigen 1 (EBNA1) and EBNA2 play roles in plasmid maintenance and cellular proliferation/transformation, respectively, whereas EBNA3 proteins (A, B, and C; products of three tandemly repeated homologous genes) appear to control the expression of EBNA and other latency proteins through specifically targeted promoter repression. ${ }^{126-133}$ In the case of HHV-8, the product of ORF73, referred to as LNA or LANA, has been detected in all Kaposi's sarcoma and primary effusion lymphoma cells latently infected with HHV-8, where the protein localises in the nuclei to form punctate patterns that may represent viral DNA replication compartments. ${ }^{47} 486465134135$ It is thought that both EBNA1 and LNA, which recognise and bind to (or near to) latency replication origins, allow segregation of viral genomes during cell division by their co-association with chromosomes, irrespective of other potential roles in viral replication. Homologues of EBNAs (1, 2, and 3) and LNA are specified by other $\gamma_{1}$ and $\gamma_{2}$ herpesviruses (with the exception of EHV-2), respectively, although their roles (and expression patterns, for the LNA homologues) have not been defined. It is notable that the homologues of EBNA2 and LNA are highly diverged relative to other conserved genes, and, indeed, that EBNA2 and EBNA3 proteins from different EBV isolates group into two subtypes, which show a degree of divergence that is reminiscent of the A, B, and C subtypes of HVS STP. 25262831136137 The predicted products of most of the ORF73 genes contain a variable number of repetitive elements comprising acidic residues, and differences in the lengths of this domain in different HHV-8 isolates have been reported. ${ }^{138}$ For EBNA2, at least, sequence divergence between the EBV and herpesvirus papio (HVP) encoded proteins, although extensive, would appear not to affect major conserved functions, because motifs necessary for nuclear localisation, transactivation, and interactions with CBF1, SKIP, and $\operatorname{Sin} 3 \mathrm{~A}$ (important for transcriptional control of EBNA2 targeted promoters) are conserved (SD Hayward, 2000, personal communication). ${ }^{128129139140}$ Conservation of function despite structural divergence would also be predicted for the $\gamma_{2}$ ORF73 encoded proteins, and perhaps functional domains are represented by the acidic repeats and other limited regions of structural similarity shared by these homologues. However, it must be noted that latent transcription of the ORF73 locus, within the divergent $\gamma D L-D$ region, has been reported only for HHV-8 and MHV-68, with the latter detected only by reverse transcription polymerase chain reaction (RT-PCR). ${ }^{125} 141$ 
HHV-8 and RRV cytokines and IRFs

Of evolutionary relevance and potential importance with respect to viral pathogenesis are the findings that HHV-8 and RRV each encode homologues of IL-6, chemokines, and IRFs, genes not present in any other sequenced $\gamma$-herpesvirus. Therefore, these genes might have functions that have a bearing on the speciation and/or particular pathogenic properties of these Kaposi's sarcoma and fibromatosis associated viruses. The cytokines are encoded by sequences within the $\gamma$ DL-B locus, whereas the IRFs, of which there are four and eight copies in HHV-8 and RRV, respectively, are present within a distinct locus that disrupts $\gamma$-herpesvirus gene block IV (fig 1); presumably, genes within the IRF loci of HHV-8 and RRV were evolutionarily recently acquired. The degrees of amino acid sequence similarities between the RRV and HHV-8 encoded IRFs and between these IRFs and their cellular homologues suggest that HHV-8 K9 represents the ancestral herpesvirus gene from which the other HHV-8 and RRV IRF genes were derived. ${ }^{26} \mathrm{~K} 9$ is most closely related to human IRF $3{ }^{25}$ With regard to the chemokine genes, there are three specified by HHV-8 and one specified by RRV. The HHV-8 K4 and K6 gene products are most similar to human MIP- $1 \alpha$ (38\% and $45 \%$ amino acid identity, respectively), of those cellular chemokines that are known, whereas the $\mathrm{K} 4.5$ protein has no clear nearest relative among the characterised endogenous chemokines. The fact that the K4 (MIP-1B or MIP-II) and K6 (MIP-1A or MIP-I) specified proteins are more closely related to each other ( $50 \%$ identity) than to human MIP- $1 \alpha$ indicates that K4 and K6 have arisen by duplication within the HHV-8 genome; the K4.5 (BCK or MIP-III) gene might have arisen through gene duplication or may have been acquired from the host cell independently. The MIP gene of RRV (specified by R3), also occurring within the $\gamma \mathrm{DL}-\mathrm{B}$ locus, is likely to share its origins with HHV-8 $\mathrm{K} 4$, with which it shares greatest amino acid sequence similarity ( $32 \%$ identity) ${ }^{26}$ Finally, the collinear IL- 6 gene homologues in HHV-8 and RRV are also likely to share their evolutionary origin. However, whereas the IL-6 protein specified by $\mathrm{K} 2$ of $\mathrm{HHV}-8$ shows clear, although diverged, sequence similarity to human IL-6 (25\% identity), the RRV protein (encoded by R2) shares very little sequence similarity to either the rhesus macaque or HHV-8 IL-6 proteins (18\% and 13\% identity, respectively). Notwithstanding, the R2 protein, in addition to the product of $\mathrm{K} 2$, is functional in various assays. ${ }^{75} 90142143$

The roles of the HHV-8 and RRV cytokines and IRFs in virus biology and pathogenesis remain to be determined. It has been shown that vMIP-1A (vMIP-I) and vMIP-1B (vMIPII) bind a broad range of CC chemokine receptors and at least one CXC chemokine receptor (CXCR4), but in most cases interaction does not result in receptor signalling, indicating that antagonist functions may be biologically relevant..$^{90} 144145$ However, vMIP-1A and vMIP-1B do interact productively with
CCR8 (present on $\mathrm{T}$ helper type 2 (Th2) cells), as does BCK (ORF4.5 product) with Th2 expressed CCR4, suggesting that these viral chemokines might lead to polarisation of the immune response away from Th1 mediated cell lysis, thereby helping HHV-8 infected cells to evade the immune response. ${ }^{8183146147}$ In addition, vMIP-1B has been shown to signal through CCR3 receptors, a function shared by the MCMV m131/129 product that appears to be important for virus production in vivo, probably through the promotion of virus dissemination via infiltrating leucocytes and through immune evasion. ${ }^{148} 149 \mathrm{~A}$ role in virus dissemination through neutrophils has been proposed for the CXC chemokine product of HCMV UL146, which signals through CXCR2. ${ }^{150} \mathrm{HHV}-8$ vMIP-1A, vMIP-1B, and BCK have been shown to effect angiogenesis in a chick chorioallantoic membrane assay, suggesting that they might play roles in the development of Kaposi's sarcoma. ${ }^{144} 147$ The precise in vivo functions and potential pathogenic effects of the HHV-8 and RRV chemokines remain to be determined. However, it seems possible that common functions of herpesvirus encoded chemokines include immune evasion and virus dissemination, of importance to both $\beta$-herpesviruses and $\gamma$-herpesviruses, irrespective of the evolutionary origins of these genes.

The vIL- 6 proteins of HHV-8 and RRV have potential roles in pathogenesis. IL- 6 has long been implicated in the development and progression of Kaposi's sarcoma and multicentric Castleman's disease, with which HHV-8 is associated, and also diseases such as multiple myeloma. ${ }^{151-154}$ More recently, human IL-6 (hIL-6) and HHV-8 vIL-6 have been implicated as mitogenic factors in $\mathrm{HHV}-8$ associated primary effusion lymphoma. ${ }^{155} 156 \mathrm{HHV}-8$ vIL-6, like the viral chemokines, has been shown to effect angiogenesis and to enhance tumour formation in an animal model system, effects mediated in part through vascular endothelial growth factor (VEGF) ${ }^{157}$ vIL-6, in contrast to endogenous IL-6 proteins, is not dependent on the IL- 6 receptor $\alpha$-component (gp80, IL-6R) for cell signalling through the gp130 signal transducer, although IL-6R appears to be able to form complexes with vIL-6 and gp130 and to enhance vIL-6 signalling. ${ }^{158} 159$ IL-6R independent signalling by vIL- 6 indicates that it might have a less restricted target cell range and greater ability to effect signal transduction than its IL-6R dependent endogenous counterpart, a feature that might be important in the development of HHV-8 associated disease. The importance of the divergence of RRV vIL-6 from its cellular and HHV-8 homologues is open to speculation, but it is possible that it reflects differences in receptor recognition that result in expanded target cell range, or other effects that are of advantage to RRV during latency or lytic replication. For HHV-8, it has been established that vIL-6 can be expressed during latency (or at least in the absence of full productive replication), although its expression is induced during lytic replication. ${ }^{7590160161}$ Its expression, to varying degrees, in primary effusion 
lymphoma, multicentric Castleman's disease, and Kaposi's sarcoma is consistent with its hypothesised role in HHV-8 pathogenesis.

The presence of IRF homologues in HHV-8 and RRV is important because it indicates a novel viral strategy for manipulating cellular signalling pathways that could be relevant to viral pathogenesis. It has been shown that the K9 gene of HHV-8 is expressed in primary effusion lymphoma cells and that its product, vIRF-1, inhibits IRF-1 mediated IFN induction of cell apoptosis, effectively blocking the activation of tumour suppressor pathways to enable the survival of infected cells. ${ }^{849092}$ A possible consequence of vIRF-1 function is to promote cellular transformation in vivo, thereby contributing to the development of primary effusion lymphoma and possibly other neoplasms. vIRF-1 expressed stably in NIH3T3 cells leads to cell transformation, as measured by morphological changes, cell growth in soft agar and at reduced serum concentrations, and the formation of tumours in nude mice. ${ }^{84}{ }^{92}$ vIRF-2, encoded by HHV-8 K11.1 (fig 1), is likely to have functions similar to vIRF-1, in that it has been established that it can inhibit cellular IRF-1 and IRF-3 mediated transcription of the IFN- $\alpha$ gene promoter. ${ }^{162}$ vIRF-1 and vIRF-2 appear to mediate their effects at least in part through direct binding to and inhibition of cellular IRFs, and by competitive binding with cellular transcription factors to the p300 transcriptional coactivator. ${ }^{80}{ }^{162}$ In addition, vIRF-2 can bind directly to RelA (p65) promoter binding sites, thereby inhibiting IFN signalling through nuclear factor $\kappa \mathrm{B}(\mathrm{NF}-\kappa \mathrm{B}){ }^{80}$ It is likely that the other vIRF genes of HHV-8 and those of RRV encode similar activities that serve to inhibit the cell's normal antiviral response to infection. The pathogenic consequences of these functions, which inhibit tumour suppressor pathways, might be to promote cell growth and neoplasia.

\section{$\gamma$-Herpesvirus general cellular gene homologues}

Several cellular gene homologues other than those included among the "core" herpesvirus genes have been identified in the $\gamma$-herpesviruses, many of these being unique to this subfamily. As indicated in table 2, these can be divided into two groups, those that are generally conserved among $\gamma$-herpesvirus members and those that are present only in one or a few members of the subfamily. This distinction is important because, as stated previously, those genes that are common among many viruses are likely to specify general functions and properties characteristic of the subfamily, whereas virus specific genes may confer unique properties that at least in part account for distinctive biological properties of individual viruses. On this basis, the " $\gamma$ general" genes listed in table 2 would be predicted to specify functions of general selective advantage in the context of the biological niche occupied by the $\gamma$-herpesviruses (or $\gamma_{1}$ or $\gamma_{2}$ subgroups) and in the genetic context (genomes) in which they are present. Genes specific and common to $\gamma_{1}$ or $\gamma_{2}$ herpesviruses-for example EBNAs $\left(\gamma_{1}\right)$ and LNA $\left(\gamma_{2}\right)$, might specify functions that contribute to the distinctive properties of these two groups of viruses or allow them to replicate in different cellular environments.

GCR, cyclin-D, bcl-2, vFLIP, and FGARAT genes are essentially $\gamma$ common genes, even though cyclin-D and vFLIP are found only in the $\gamma_{2}$ viruses (but not all) and GCR homologues distinct from ORF74 are present in the $\gamma$ DL-B loci of EBV, EHV-2, and AHV-1, with EHV-2 also specifying an ORF74 equivalent and a third GCR gene (E1, encoding a functional chemokine receptor) within the terminal direct repeat units. ${ }^{731} 163$ Although EBV does not encode an ORF74-type GCR or a cyclin-D gene, it does induce the expression of homologous cellular genes in lytically infected cells. ${ }^{164-166}$ The functions of bcl-2 and vFLIP are likely to be important during lytic infection, counteracting antiviral apoptotic responses of the infected cell to prolong cell survival for greater production of virus progeny. ${ }^{167-169}$ However, vFLIP is known to be expressed during latency in $\mathrm{HHV}-8$, and it is possible, therefore, that it serves a role in protecting latently infected cells from apoptosis. ${ }^{170}$ The cyclin-D gene of HHV-8 is also transcribed during latency, consistent with the idea that the $\gamma$-herpesvirus cyclin-D homologues might play a role in virus induced transformation. ${ }^{171-174}$ Regardless of whether this is the case, it is apparent that at least one viral cyclin, that specified by MHV-68, is required for the reactivation of lytic replication from latency in vivo; a cyclin deletion mutant of MHV-68, although able to undergo normal productive replication in culture and establish latency in infected mice, showed reduced lytic replication in vivo and was almost completely abrogated in its ability to reactivate from latency (an effect unrelated to replication efficiency before the establishment of latency). ${ }^{175} \mathrm{MHV}-68$ cyclin is known to be expressed during lytic replication, not during latency. ${ }^{141}{ }^{176}$ Viral cyclin D proteins might be essential for establishing the intracellular environment conducive for lytic replication in the particular cell types normally latently infected by many of the $\gamma_{2}$ herpesviruses.

\section{Conclusions}

In this review I have outlined what I consider to be the main important features regarding the genetic composition and organisation of the $\gamma$-herpesvirus genomes and given brief descriptions of gene functions that are likely to be particularly relevant to $\gamma$-herpesvirus evolution, biology, and pathogenesis. The main conclusions deriving from genetic comparisons are that: (1) $\gamma$-herpesvirus genomes, like those of the other herpesvirus subfamilies, are organised into conserved gene blocks; (2) in the $\gamma$-herpesviruses, these conserved gene blocks are separated by coincident divergent loci ( $\gamma \mathrm{DL}-\mathrm{A}$ to $\gamma \mathrm{DL}-\mathrm{D})$; (3) homologous genes within the divergent loci often show unusually high degrees of sequence divergence, relative to other homologous genes; (4) acquisition of cel- 
lular gene homologues by the $\gamma$-herpesviruses is a relatively common event (on an evolutionary time scale), suggesting that these viruses can readily acquire new functions that might serve to drive speciation by allowing the occupation of new biological niches; and (5) gene acquisition, gene loss, and high frequency mutational changes at the major $\gamma$-herpesvirus divergent loci might be facilitated by the presence of repetitive sequence elements and/or replication origins. Another important point is that gene functions, although not necessarily encoded amino acid sequences, might correlate with genetic loci, allowing predictions to be made about the possible functions of collinear, apparently non-homologous genes. EBV, HVS, $\mathrm{HHV}-8$, and RRV each specify genes within $\gamma$ DL-A that have been shown to have transforming functions in in vitro and/or in vivo experimental systems. Furthermore, the LMP-2 and K15 genes at the right ends of the genomes of EBV and HHV-8 appear to be functionally equivalent; these share properties with HVS-C Tip and HVA Tio (at the left ends of their genomes). The $\gamma$ DL-D region can perhaps be thought of generally as a "latency maintenance" locus; genes in EBV, HVS, and HHV-8 $\gamma$ DL-D have been shown to be transcribed during latency, and $\gamma \mathrm{DL}-\mathrm{D}$ genes include LMP2 and EBNA2 (BYRF1) of EBV, and the $\gamma_{2}$ genes LNA (ORF73, HHV-8), kaposin (ORFK12, HHV-8), K15 (HHV-8), cyclin (ORF72), vFLIP (ORF71), and GCR (ORF74), which can/could play roles in the maintenance of latency (LMP2, EBNA2, LNA, and K15), maintenance of cell survival/ proliferation (kaposin, vFLIP, cyclin, and GCR), or in reactivation from latency (cyclin). Lytic origins of replication might be common to the $\gamma \mathrm{DL}-\mathrm{D}$ loci. The $\gamma \mathrm{DL}-\mathrm{C}$ locus in EBV contains Zta and EBNA1/3 coding sequences and, therefore, is, like $\gamma \mathrm{DL}-\mathrm{D}$, a "latency maintenance" locus in this $\gamma$-herpesvirus. In the $\gamma_{2}$ viruses, the functions of the few encoded $\gamma \mathrm{DL}-\mathrm{C}$ genes have not been defined, although HHV-8 would appear to have a highly diverged homologue (K8) of Zta. The $\gamma$ DL-B locus ranges from apparently non-coding (HVA) to a "sink" for diverse cellular gene homologues (HHV-8). In each virus, this locus is likely to contain a lytic replication origin (as has been shown for EBV and suspected for $\mathrm{HHV}-8$; repetitive elements, possibly indicative of replication origins, have been noted for some of the other $\gamma_{2}$ herpesviruses). The IRF loci of HHV-8 and RRV are not present in the other sequenced $\gamma$-herpesviruses, and it is likely that the IRF genes are involved in the inhibition of IFN mediated antiviral responses, perhaps contributing to viral pathogenesis through effects on cell growth and transformation. Other virus specific genes (not conserved among most $\gamma$-herpesviruses), such as vIL-6 and possibly the v-chemokines (also present in HHV-8 and RRV), might contribute to the unique and distinctive properties of the respective viruses; however, such genes that are present in herpesviruses outside the $\gamma$-herpesvirus subfamily, for example $\mathrm{Ox}-2$,
GCRs, and chemokines, might specify more generalised functions.

The present database of $\gamma$-herpesvirus genome sequences has provided insight into the evolution of these viruses and allowed the identification of genes likely to contribute to virus specific properties. Further herpesvirus genome sequencing will allow us to expand our understanding of the molecular basis of herpesvirus evolution and diversity.

I am grateful to Dr S D Hayward for helpful discussions.

1 Gompels UA, Nicholas J, Lawrence G, et al. The DNA equence of human herpesvirus-6: structure, coding content, and genome evolution. Virology 1995;209:29-51.

2 Albrecht J-C, Nicholas J, Biller D, et al. Primary structure of the herpesvirus saimiri genome. F Virol 1992;66:5047-58.

3 Bublot M, Lomonte P, Lequarre A-S, et al. Genetic relationships between bovine herpesvirus 4 and gammaherpesviruses Epstein-Barr virus and herpesvirus saimiri. Virology 1992;190:654-65.

4 Kouzarides T, Bankier AT, Satchwell SC, et al. Large-scale rearrangement of homologous regions in the genomes of HCMV and EBV. Virology 1987;157:387-413.

5 McGeoch DJ. The genomes of human herpesviruses: contents, relationships, and evolution. Anпи Rev Microbiol 1989;43:235-65.

6 McGeoch DJ, Dalrymple MA, Davison AJ, et al. The complete DNA sequence of the long unique region of herpes plete DNA sequence of the long unique region of
simplex virus type 1 . F Gen Virol 1988;69:1531-4.

7 Telford EAR, Watson MS, Aird HC, et al. The DNA sequence of equine herpesvirus 2. F Mol Biol 1995;249: $520-8$.

8 Telford EAR, Watson MS, McBride K, et al. The DNA sequence of equine herpesvirus-1. Virology 1992;189:30416.

9 Telford EAR, Watson MS, Perry J, et al. The DNA sequence of equine herpesvirus-4. F Gen Virol 1998;79:1197-203.

$10 \mathrm{McGeoch}$ DJ, Cook S, Dolan A, et al. Molecular phylogeny and evolutionary timescale for the family of mammalian herpesviruses. F Mol Biol 1995;247:443-58.

11 Chen M-J, Shimada T, Davis-Moulton A, et al. The functional human dihydrofolate reductase gene. $f$ Biol Chem 1984;259:3933-43.

12 Lockridge KM, Zhou S-S, Kravitz RH, et al. Primate cytomegaloviruses encode and express an IL-10-like pytomegaloviruses encode and Virology 2000;268:272-80.

13 Megaw AG, Rapaport D, Avidor B, et al. The DNA sequence of the RK strain of human herpesvirus 7. Virology 1998;244:119-32

14 Ishfort R, Jones D, Kost R, et al. Retrovirus insertion into herpesvirus in vitro and in vivo. Proc Natl Acad Sci US A 1992;89:991-5.

15 Kost R, Jones D, Ishfort R, et al. Retrovirus insertion into herpesvirus: characterization of a Marek's disease virus harboring a solo LTR. Virology 1993;192:161-9.

16 Thomson BJ, Efstathiou S, Honess RW. Acquisition of the human adeno-associated virus type-2 rep gene by human herpesvirus-6. Nature 1991;351:78-80.

17 Harrington LA, Grieder CW. Telomerase primer-specificity and chromosome healing. Nature 1991;353:451-4.

18 Kishi $M$, Harada $H$, Takahashi $M$, et al. A repeat sequence, GGGTTA, is shared by DNA of human herpesvirus 6 and GGGTTA, is shared by DNA of human herpe
Marek's disease virus. $\mathcal{F}$ Virol $1988 ; 62: 4824-7$.

19 Secchiero P, Nicholas J, Deng H, et al. Identification of human telomeric repeat motifs at the genome termini of human herpesvirus 7: structural analysis and heterogeneity. f Virol 1995;69:8041-5.

20 Thomson BJ, Dewhurst S, Gray D. Structure and heterogeneity of the a sequences of human herpesvirus 6 strain variants U1102 and Z29 and identification of human telomeric repeat sequences at the genome termini. $\mathcal{F}$ Virol 1994;68:3007-14.

21 Gompels UA, Macaulay HA. Characterization of human telomeric repeat sequences from human herpesvirus 6 and relationship to replication. f Gen Virol 1995;76:451-8.

22 Chee MS, Bankier AT, Beck S, et al. Analysis of the protein coding content of the sequence of human cytomegalovirus strain AD169. Curr Top Microbiol Immunol 1990;154:12569 .

23 Albrecht J-C. Primary structure of the herpesvirus ateles genome. F Virol 2000;74:1033-7.

24 Neipel F, Albrecht J-C, Fleckenstein B. Cell-homologous genes in the Kaposi's sarcoma-associated rhadinovirus human herpesvirus 8 : determinants of its pathogenicity? $f$ Virol 1997;71:4187-92.

25 Russo JJ, Bohenzky RA, Chien M-C, et al. Nucleotide sequence of the Kaposi sarcoma-associated herpesvirus
(HHV). Proc Natl Acad Sci U S A 1996;93:14862-7.

26 Searles RP, Bergquam EP, Axthelm MK, et al. Sequence and genomic analysis of a rhesus macaque rhadinovirus with similarity to Kaposi's sarcoma-associated herpesvirus/ with similarity to Kaposi's sarcoma-associated herp
human herpesvirus 8. F Virol 1999;73:3040-53. 27 van Santen VL. Characterization of bovine herpesvirus 4 24 . 
28 Virgin HW, IV, Latreille P, Wamsley P, et al. Complete sequence and genomic analysis of murine gammaherpesvi71:5894-904.

29 Baer R, Bankier AT, Biggin MD, et al. DNA sequence and expression of the B95-8 Epstein-Barr virus genome. Nature 1984;310:207-11.

30 Parker BD, Bankier AT, Satchwell SC, et al. Sequence and transcription of Raji Epstein-Barr virus DNA spanning the B95-8 deletion region. Virology 1990;179:339-46.

31 Ensser A, Pflanz R, Fleckenstein B. Primary structure of the alcelaphine herpesvirus 1 genome. $\mathcal{F}$ Virol 1997;71:651725.

32 Inoue N, Dambaugh TR, Rapp JC, et al. Alphaherpesvirus origin-binding protein homolog encoded by human herpesvirus $6 \mathrm{~B}$, a betaherpesvirus, binds to nucleotide sequences that are similar to ori regions of alphaherpesviruses. F Virol 1994;68:4126-36.

33 Lawrence GL, Nicholas J, Barrell BG. Human herpesvirus 6 (strain U1102) encodes homologues of the conserved herpesvirus glycoprotein $\mathrm{gM}$ and the alphaherpesvirus originbinding protein. 7 Gen Virol 1995;76:147-52.

34 Nicholas J. Determination and analysis of the complete nucleotide sequence of human herpesvirus 7. F Virol 1996; 70:5975-89.

35 Anders DG, Kacica MA, Pari GS, et al. Boundaries and structure of human cytomegalovirus oriLyt, a complex origin for lytic phase DNA replication. F Virol 1992;66:337384 .

36 Dewhurst S, Dollard SC, Pellett PE, et al. Identification of a lytic phase origin of DNA replication in human herpesvirus lytic phase origin of DNA replication in

37 Olivo PD, Nelson NJ, Challberg MD. Herpes simplex virus DNA replication: the UL9 gene encodes an origin-binding protein. Proc Natl Acad Sci U S A 1988;85:5414-18.

38 Weir HM, Stow ND. Two binding sites for the herpes simplex virus type 1 UL9 protein are required for efficien activity of the oriS replication origin. $\mathcal{F}$ Gen Virol 1990;71: 1379-85.

39 Honess RW, Gompels UA, Barrell BG, et al. Deviations from expected frequencies of $\mathrm{CpG}$ dinucleotides in herpesvirus DNAs may be diagnostic of differences in the states of their latent genomes. F Gen Virol 1989;70:837-55.

40 Karlin S, Doefler W, Cardon LR. Why is CpG suppressed in the genomes of virtually all small eukaryotic viruses but not
in those of large eukaryotic viruses? F Virol $1994 ; 68: 2889$ in thos.

41 Nicholas J. Nucleotide sequence analysis of a $21-\mathrm{kbp}$ region of the genome of human herpesvirus- 6 containing homologues of human cytomegalovirus major immediate-early and replication genes. Virology 1994;204:738-50.

42 Rawlinson WD, Farrell H, Barrell BG. Analysis of the complete nucleotide sequence of murine cytomegalovirus. $f$ Virol 1996;70:8833-49.

43 Sandford GR, Ho K, Burns WH. Characterization of the major locus of immediate-early genes of rat cytomegalovirus. F Virol 1993;67:4093-103.

44 Rose TM, Strand KB, Schultz ER, et al. Identification of two homologs of the Kaposi's sarcoma-associated herpesvitwo homologs of the Kaposi's sarcoma-associated herpesviof different macaque species. F Virol 1997;71:4138-44.

45 Nicholas J, Ruvolo VR, Zong J, et al. A single 13-kilobase divergent locus in the Kaposi sarcoma-associated herpesvirus (human herpesvirus 8) genome contains nine open reading frames that are homologous to or related to cellular proteins. F Virol 1997;71:1963-74.

46 Nicholas J, Cameron KR, Coleman H, et al. Analysis of nucleotide sequence of the rightmost $43 \mathrm{kbp}$ of herpesvirus saimiri (HVS) L-DNA: general conservation of genetic organization between HVS and Epstein-Barr virus. Virology 1992;188:296-310.

47 Ballastas ME, Chatis PA, Kaye KH. Efficient persistence of extrachromosomal KSHV DNA mediated ciated nuclear antigens. Science 1999;284:641-4.

48 Cotter MA, Robertson ES. The latency-associated nuclear antigen tethers the Kaposi's sarcoma-associated herpesvirus genome to host chromosomes in body cavity-based lymphoma cells. Virology 1999;264:254-64

49 Hammerschmidt W, Sugden B. Identification and characterization of oriLyt, a lytic origin of DNA replication of Epstein-Barr virus. Cell 1988;55:427-33.

50 Kung S-H, Medveczky PG. Identification of a herpesvirus saimiri cis-acting DNA fragment that permits stable replication of episomes in transformed T cells. F Virol 1996;70: 1738-44.

51 Nicholas J, Zong J-C, Alcendor DJ, et al. Novel organizational features, captured cellular genes and strain variability
within the genome of KSHV/HHV-8. F Natl Cancer Inst Monogr 1998;23:79-88.

52 Rawlins DR, Milman G, Hayward SD, et al. Sequencespecific DNA binding of the Epstein-Barr virus nuclear antigen (EBNA-1) to clustered sites in the plasmid maintenence region. Cell 1985;42:859-68.

53 Ryon JJ, Fixman ED, Houchens C, et al. The lytic origin of herpesvirus papio is highly homologous to Epstein-Bar virus ori-Lyt: evolutionary conservation of transcriptional activation and replication signals. F Virol 1993;67:4006-16.

54 Yates JL, Warren N, Reisman D, et al. A cis-acting element from the Epstein-Barr viral genome that permits stable replication of recombinant plasmids in latently infected cells. Proc Natl Acad Sci U S A 1984;81:3806-10.

55 Yates JL, Warren N, Sugden B. Stable replication of plasmids derived from Epstein-Barr virus in various mammalian cells. Nature 1995;313:812-15.
56 Fixman ED, Hayward GS, Hayward SD. Trans-acting requirements for replication of Epstein-Barr virus ori-Lyt. f Virol 1992;66:5030-9.

57 Fixman ED, Hayward GS, Hayward SD. Replication of Epstein-Barr virus ori Lyt: lack of dedicated virallyencoded origin-binding protein and dependence on Zta in cotransfection assays. F Virol 1995;69:2998-3006.

58 Gruffat H, Portes-Sentis S, Sergeant A, et al. Kaposi's sarcoma-associated herpesvirus (human herpesvirus-8) encodes a homologue of the Epstein-Barr virus bZIP protein EB1. I Gen Virol 1999;80:557-61.

59 Lin S-F, Robinson DR, Miller G, et al. Kaposi's sarcomaassociated herpesvirus encodes a bZIP protein with homology to BZLF1 of Epstein-Barr virus. F Virol 1999;73:190917.

60 Rooney CM, Rowe DT, Ragot T, et al. The spliced BZLF1 gene of Epstein-Barr virus (EBV) transactivates an early
EBV promoter and induces the virus productive cycle. $\mathcal{F}$ Virol 1989;63:3109-16.

61 Schepers A, Pich D, Hammerschmidt W. Activation of oriLyt, the lytic origin of DNA replication of Epstein-Barr virus, by BZLF1. Virology 1996;220:367-76.

62 Seaman WT, Ye D, Wang RX, et al. Gene expression from the ORF50/K8 region of Kaposi's sarcoma-associated herpesvirus. Virology 1999;263:436-49.

63 Zhu FX, Cusano T, Yuan Y. Identification of the immediateearly transcripts of Kaposi's sarcoma-associated herpesvirus. $\mathcal{F}$ Virol 1999;73:5556-67.

64 Kellam P, Boshoff C, Whitby D, et al. Identification of a major latent nuclear antigen (LANA) in the human herpesvirus 8 genome. F Hum Virol 1997;1:19-29.

65 Rainbow L, Platt GM, Simpson GR, et al. The 222- to 234kilodalton latent nuclear protein (LNA) of Kaposi's sarcoma-associated herpesvirus (human herpesvirus 8) is encoded by orf73 and is a component of the latencyassociated nuclear antigen. F Virol 1997;71:5915-21.

66 McGeoch DJ, Davison AJ. The decent of human herpesvirus 8. Semin Cancer Biol 1999;9:201-9.

67 Damania B, Choi J-K, Jung JU. Signaling activities of gammaherpesvirus membrane proteins. F Virol 2000;74:1593601.

68 Hayward GS. KSHV strains: the origins and global spread of the virus. Semin Cancer Biol 1999;9:187-99.

69 Zong J-C, Ciufo DM, Alcendor DJ, et al. High level variability in the ORF-K1 membrane protein gene at the left end of the Kaposi's sarcoma-associated herpesvirus genome defines four major virus subtypes and multiple clades in different human populations. F Virol 1999;73: 4156-70.

70 Biesinger B, Trimble JJ, Desrosier RC, et al. The divergence between two oncogenic herpesvirus saimiri strains in a genomic region related to the transforming phenotype. Virology 1990;176:505-14.

71 Glenn M, Rainbow L, Aurade F, et al. Identification of a spliced gene from Kaposi's sarcoma-associated herpesvirus encoding a protein with similarities to latent membrane proteins 1 and $2 \mathrm{~A}$ of Epstein-Barr virus. F Virol 1999;73:6953-63.

72 Lee H, Trimble J, Yoon DW, et al. Genetic variation of herpesvirus saimiri subgroup A transforming protein and its association with cellular src. 7 Virol 1997;71:3817-25.

73 Medveczky P, Szomolanyi E, Desrosier RC, et al. Classification of herpesvirus saimiri into three groups based on extreme variation in a DNA region required for oncogenicity. F Virol 1984;52:938-44

74 Poole LJ, Zong J-C, Ciufo DM, et al. Comparison of genetic variability at multiple loci across the genomes of the major subtypes of Kaposi's sarcoma-associated herpesvirus reveals evidence for recombination and for two distinct types of open reading frame K15 alleles at the right-hand end. $\mathcal{F}$ Virol 1999;73:6646-60.

75 Nicholas J, Ruvolo VR, Burns WH, et al. Kaposi's sarcomaassociated human herpesvirus- 8 encodes homologues of macrophage inflammatory protein-1 and interleukin-6. Nat Med 1997;3:287-92

76 MacDonald MR, Li XY, Virgin HW. Late expression of a beta chemokine homolog by murine cytomegalovirus. $\mathcal{f}$ Virol 1997;71:1671-8

77 MacDonald MR, Burney MW, Resnick SB, et al. Spliced mRNA encoding the murine cytomegalovirus chemokine homolog predicts a beta chemokine of novel structure. $\mathcal{F}$ Virol 1999;73:3682-91.

78 Penfold ME, Dairaghi DJ, Duke GM, et al. Cytomegalovirus encodes a potent alpha chemokine. Proc Natl Acad Sci U S A 1999;96:9839-44.

79 Albrecht J-C, Nicholas J, Cameron KR, et al. Herpesvirus saimiri has a gene specifying a homolog of the cellular membrane glycoprotein CD59. Virology 1992;190:527-30.

80 Burysek L, Yeow W-S, Pitha PM. Unique properties of a second human herpesvirus 8 -encoded interferon regulatory factor (vIRF-2). F Hum Virol 1999;2:19-32.

81 Dairaghi DJ, Fan RA, McMaster BE, et al. HHV-8-encoded VMIP-I selectively engages chemokine receptor CCR8. Agonist and antagonist profiles of viral chemokines. F Biol Chem 1999;274:21569-74.

82 Duboise M, Guo J, Czajak S, et al. A role for herpesvirus saimiri orf14 in transformation and persistent infection. $\mathcal{F}$ Virol 1998;72:6770-6.

83 Endres MJ, Garlisi CG, Xiao H, et al. The Kaposi's sarcoma-related herpesvirus (KSHV)-encoded chemokine vMIP-I is a specific agonist for the CC-chemokine receptor (CCR)8. F Exp Med 1999;189:1993-8. 
84 Gao S-J, Boshoff C, Jayachandran S, et al. KSHV ORF K9 (vIRF) is an oncogene which inhibits the interferon signaling pathway. Oncogene 1997;15:1979-85.

85 Jones $\mathrm{KD}$, Aoki Y, Chang $\mathrm{Y}$, et al. Involvement of interleukin-10 (IL-10) and viral IL-6 in the spontaneous growth of Kaposi's sarcoma herpesvirus-associated infected primary effusion lymphoma cell lines. Blood 1999;94:2871-97.

86 Knappe A, Hiller C, Niphuis H, et al. The interleukin-17 gene of herpesvirus saimiri. F Virol 1998;72:5797-801.

87 Knappe A, Hiller C, Thurau M, et al. The superantigenhomologous viral immediate-early gene ie14/vsag in herpesvirus saimiri transformed human $\mathrm{T}$ cells. $\mathcal{F}$ Virol 1997;71:9124-33.

88 Fodor WL, Rollins SA, Bianco-Caron S, et al. The complement control protein homolog of herpesvirus saimiri regulates serum complement by inhibiting $\mathrm{C} 3$ convertase activity. $\mathcal{F}$ Virol 1995;69:3889-92.

89 Moore PS, Chang Y. Antiviral activity of tumor-suppressor pathways: clues from molecular piracy by KSHV. Trends Genet 1998;14:144-50.

90 Moore PS, Boshoff C, Weiss RA, et al. Molecular mimicry of human cytokine and cytokine response pathway genes by KSHV. Science 1996;274:1739-44.

91 Neipel F, Fleckenstein B. The role of HHV-8 in Kaposi's sarcoma. Semin Cancer Biol 1999;9:151-64.

$92 \mathrm{Li} \mathrm{M}$, Lee H, Guo J, et al. Kaposi's sarcoma-associated herpesvirus viral interferon regulatory factor. F Virol 1998;72 5433-40

93 Yao Z, Maraskovsky E, Spriggs MK, et al. Herpesvirus saimiri open reading frame 14 , a protein encoded by $\mathrm{T}$ lymphotropic herpesvirus, binds to MHC class II molecules and stimulates T cell proliferation. F Immunol 1996; 156:3260-6.

94 Zimring JC, Goodbourn S, Offermann MK. Human herpesvirus 8 encodes an interferon regulatory factor (IRF)
homolog that represses IRF-1-mediated transcription. 7 homolog that repres
Virol 1998;72:701-7.

95 Biesinger B, Tsygankov AY, Fickenscher H, et al. The product of herpesvirus saimiri open reading frame 1 (tip) interacts with T cell-specific kinase p $56^{\text {lck }}$ in transformed cells. $\mathcal{F}$ Biol Chem 1995;270:4729-34.

96 Cohen JI, Wang JM, Kieff E. Epstein-Barr virus nuclear protein 2 is a key determinant of lymphocyte transformation. Proc Natl Acad Sci U S A 1989;86:9558-62.

97 Damania $\mathrm{B}, \mathrm{Li} \mathrm{M}$, Choi JK, et al. Identification of the R1 oncogene and its protein product from the rhadinovirus of rhesus mokeys. F Virol 1999;73:5123-31.

98 Duboise SM, Guo J, Czajak S, et al. STP and Tip are essential for herpesvirus saimiri oncogenicity. 7 Virol 1998;72. 1308-13.

99 Kaye KM, Izumi KM, Kieff E. Epstein-Barr virus latent membrane protein 1 is essential for B-lymphocyte growth
transformation. Proc Natl Acad Sci U S A 1993;90:9150-4.

100 Lee H, Choi JK, Li M, et al. Role of cellular tumor necrosis factor receptor-associated factors in NF- $\mathrm{KB}$ activation and lymphocyte transformation by herpesvirus saimir STP. $\mathcal{F}$ Virol 1999;73:3913-19.

101 Lee H, Veazey R, Williams K, et al. Deregulation of cell growth by the K1 gene of Kaposi's sarcoma-associated herpesvirus. Nat Med 1998;4:435-40.

102 Murthy SC, Trimble JJ, Desrosiers RC. Deletion mutants of herpesvirus saimiri define an open reading frame necessary for transformation. $\mathcal{F}$ Virol 1989;63:3307-14.

103 Devergne O, Hatzivassiliou E, Izumi KM, et al. Association of TRAF1, TRAF2, and TRAF3 with an Epstein-Barr virus LMP1 domain important for B-lymphocyte virus LMP1 domain important for B-lymphocyte transformation: rol

104 Devergne O, McFarland EC, Mosialos G, et al. Role of the TRAF binding site and NF- $\mathrm{KB}$ activation in Epstein-Barr virus latent membrane protein 1-induced cell gene expression. F Virol 1998;72:7900-8.

105 Eliopoulos AG, Blake SM, Floettmann JE, et al. EpsteinBarr virus-encoded latent membrane protein 1 activates the JNK pathway through its extreme $\mathrm{C}$ terminus via a mechanism involving TRADD and TRAF2. I Virol 1999;73:1023-35

106 Eliopoulos AG, Dawson CW, Mosialos G, et al. CD40induced growth inhibition in epithelial cells is mimicked by Epstein-Barr virus-encoded LMP1: involvement of TRAF3 as a common mediator. Oncogene 1996;13:2243TRA.

107 Izumi KM, Kieff ED. The Epstein-Barr virus oncogene product latent membrane protein 1 engages the tumor product latent membrane protein 1 engages the tumor mediate B lymphocyte growth transformation and activate mediate B lymphocyte growth transformation and activat

$108 \mathrm{Lee} \mathrm{H}$, Guo J, Li M, et al. Identification of an immunoreceptor tyrosine-based activation motif of $\mathrm{K} 1$ transforming protein of Kaposi's sarcoma-associated herpesvirus. Mo Cell Biol 1998;18:5219-28.

109 Lagunoff M, Majeti R, Weiss A, et al. Deregulated signal transduction by the K1 gene product of Kaposi's sarcomaassociated herpesvirus. Proc Natl Acad Sci U S A 1999;96: 5704-9.

110 Mosialos G, Birkenbach M, VanArsdale T, et al. The Epstein-Barr virus transforming protein LMP1 engages signaling proteins of the tumor necrosis factor receptor signaling proteins of the tu
family. Cell 1995;80:389-99.

111 Lund T, Medveczky MM, Neame PJ, et al. A herpesvirus saimiri membrane protein required for interleukin-2
independence forms a stable complex with $556^{\text {lck. }}$. Virol 1996;70:600-6.
112 Duboise SM, Lee H, Guo J, et al. Mutation of the Lck-binding motif of Tip enhances lymphoid cell activation by herpesvirus saimiri. F Virol 1998;72:2607-14

113 Jung JU, Lang SM, Jun T, et al. Downregulation of Lck-mediated signal transduction by Tip of herpesvirus saimiri. F Virol 1995;69:7814-22.

14 Miller CL, Burkhardt AL, Lee JH, et al. Integral membrane protein 2 of Epstein-Barr virus regulates reactivation from latency through dominant negative effects on protein-tyrosine kinases. Immunity 1995;2:155-66.

115 Beaufils P, Choquet D, Mamoun RZ, et al. The (YXXL/I)2 signalling motif found in the cytoplasmic segments of the bovine leukaemia virus envelope protein and Epstein-Barr virus latent membrane protein $2 \mathrm{~A}$ can elicit early and late
lymphocyte activation events. EMBO f 1993;12:5105-12.

116 Burkhardt AL, Bolen JB, Kieff E, et al. An Epstein-Barr virus transformation-associated membrane protein intervirus transformation-associated membrane protein inter7.

117 Scholle F, Longnecker R, Raab-Traub N. Epithelial cell adhesion to extracellular matrix proteins induces tyrosine phosphorylation of the Epstein-Barr virus latent membrane protein 2 :

118 Kim O-J, Yates YL. Mutants of Epstein-Barr virus with a selective marker disrupting the TP gene transform B cells and replicate normally in culture. F Virol 1993;67:7634-40.

119 Longnecker R, Miller CL, Miao XQ, et al. The last seven transmembrane and carboxy-terminal cytoplasmic domains of Epstein-Barr virus latent membrane protein 2 (LMP2) are dispensible for lymphocyte infection and growth transformation in vitro. 7 Virol 1993;67:2006-13.

120 Choi J-K, Lee BS, Shim SN, et al. Identification of a novel K15 gene at the rightmost end of the Kaposi's sarcomaassociated herpesvirus genome. F Virol 1999;74:436-46.

121 Zong J-C, Metroka C, Reitz MS, et al. Strain variability among Kaposi sarcoma-associated herpesvirus (human herpesvirus 8) genomes: evidence that a large cohort of United States AIDS patients may have been infected by a single common isolate. F Virol 1997;71:2505-11

122 Jung JU, Trimble JJ, King NW, et al. Identification of ransforming genes of subgroup $\mathrm{A}$ and $\mathrm{C}$ strains of Herpesvirus saimiri. Proc Natl Acad Sci U S A 1991;88:7051-5.

123 Medveczky MM, Szomolanyi E, Hesselton R, et al. Herpesvirus saimiri strains from three DNA subgroups have different oncogenic potentials in New Zealand White rabbits. F Virol 1989;63:3601-11

124 Albrecht J-C, Friedrich U, Kardinal C, et al. Herpesvirus ateles gene product Tio interacts with nonreceptor tyrosine kinases. F Virol 1999;73:4631-9.

125 Husain SM, Usherwood EJ, Dyson H, et al. Murine gammaherpesvirus M2 gene is latency-associated and its protein a target for CD8 ${ }^{+} \mathrm{T}$ lymphocytes. Proc Natl Acad Sci U S A 1999;96:7508-13.

126 Hsieh J-D, Hayward SD. Masking of the CBF1/RBPJ ranscriptional repression domain by Epstein-Barr virus EBNA2. Science 1995;268:560-3

127 Lee M-A, Diamond ME, Yates JL. Genetic evidence that EBNA-1 is needed for efficient, stable latent infection by Epstein-Barr virus. 7 Virol 1999;73:2974-82.

128 Ling P, Hayward SD. Contribution of conserved amino acids in mediating the interaction between EBNA2 and CBF1/RBPJk. f Virol 1995;69:1944-50.

129 Ling PD, Hsieh JJ, Ruf IK, et al. EBNA-2 upregulation of Epstein-Barr virus latency promoter utilizes a common targeting intermediate, CBF1. F Virol 1994;68:5375-83.

130 Nitsche F, Bell A, Rickinson A. Epstein-Barr virus leader protein enhances EBNA-2-mediated transactivation of latent membrane protein 1 expression: a role for the W1W2 repeat domain. F Virol 1997;71:6619-28.

131 Radkov SA, Bain M, Farrell PJ, et al. Epstein-Barr virus EBNA3C represses $\mathrm{Cp}$, the major promoter for EBNA expression, but has no effect on the promoter of the cell gene CD21. F Virol 1997;71:8552-62.

32 Radkov SA, Touitou R, Brehm A, et al. Epstein-Barr virus nuclear antigen $3 \mathrm{C}$ interacts with histone deacetylase to repress transcription. $\mathcal{F}$ Virol 1999;73:5688-97.

133 Waltzer L, Perricaudet M, Sergent A, et al. Epstein-Barr virus EBNA3A and EBNA3C proteins both repress RBPK-EBNA2-activated transcription by inhibiting the binding of RBP-Jк to DNA. $\mathcal{F}$ Virol 1996;70:5909-15.

134 Kedes DH, Lagunoff M, Renne R, et al. Identification of the gene encoding the major latency-associated nuclear antigen of the Kaposi's sarcoma-associated herpesvirus. $\mathcal{F}$ Clin Invest 1996;100:2606-10.

135 Szekely L, Kiss C, Mattsson K, et al. Human herpesvirus8-encoded LNA-1 accumulates in heterochromatinassociated nuclear bodies. F Gen Virol 1999;80:2889-900.

136 Ling PD, Ryon JJ, Hayward SD. EBNA-2 of herpesvirus papio diverges significantly from the type $A$ and type $B$ EBNA-2 proteins of Epstein-Barr virus but retains an efficient transactivation domain with a conserved hydrophobic motif. F Virol 1993;67:2990-3003.

137 Sample J, Young L, Martin B, et al. Epstein-Barr virus types 1 and 2 differ in their EBNA-3A, EBNA-3B and EBNA-3C genes. F Virol 1990;64:4084-92.

138 Gao SJ, Zhang YJ, Deng JH, et al. Molecular polymorphism of Kaposi's sarcoma-associated herpesvirus (human herpesvirus 8) latent nuclear antigen: evidence for a large repetoire of viral genotypes and dual infection with repetoire of viral genotypes and dual infection with

139 Hayward SD. Immortalisation by Epstein-Barr virus: focusing on the Notch signalling pathway. Epstein-Barr Virus Report 1999;6:151-7. 
140 Zhou S, Fujimuro M, Hsieh JJ-D, et al. SKIP, a CBF1-associated protein, interacts with the ankyrin repeat Biol 2000;20:2400-10

141 Virgin HW, Presti RM, Li XY, et al. Three distinct regions of the murine gammaherpesvirus 68 genome are transcriptionally active in latently infected mice. I Virol 1999;73: 2321-32.

142 Burger R, Neipel F, Fleckenstein B, et al. Human herpesvirus type 8 interleukin- 6 homologue is functionally active on human myeloma cells. Blood 1998;91:1858-63.

143 Kaleeba JA, Bergquam EP, Wong SW. A rhesus macaque rhadinovirus related to Kaposi's sarcoma-associated herpesvirus/human herpesvirus 8 encodes a functional homologue of interleukin-6. F Virol 1999;73:6177-81.

144 Boschoff C, Endo Y, Collins PD, et al. Angiogenic and HIV-inhibitory functions of KSHV-encoded chemokines. Science 1997;278:290-4.

145 Kledal T, Rosenkilde MM, Coulin F, et al. Broad-spectrum chemokine antagonist encoded by Kaposi's sarcomachemokine antagonist encoded by Kaposi's

146 Sozzani S, Luini W, Bianchi G, et al. The viral chemokine macrophage inflammatory protein-II is a selective Th2 macrophage inflammatory protein-II is

147 Stine JT, Wood C, Hill M, et al. KSHV-encoded CC chemokine vMIP-III is a CCR4 agonist, stimulates angiogenesis, and selectively chemoattracts TH2 cells. Blood 2000;95:1151-7.

148 Fleming P, Davis-Poynter N, Degli-Esposti M, et al. The murime cytomegalovirus chemokine homolog, m131/129, is a determinant of viral pathogenicity. F Virol 1999;73: 6800-9.

149 Saederup N, Lin YC, Dairaghi DJ, et al. Cytomegalovirusencoded beta chemokine promotes monocyte-associated viremia in the host. Proc Natl Acad Sci U S A 1999;14:10881-6.

150 Penfold ME, Dairaghi DJ, Duke GM, et al. Cytomegalovirus encodes a potent alpha chemokine. Proc Natl Acad Sci US A 1999;96:9839-44.

151 Ishiyama T, Nakamura S, Akimoto $\mathrm{Y}$, et al. Immunodeficiency and IL- 6 production by peripheral blood monocytes in multicentric Castleman's disease. Br $\mathcal{F}$ Haematol 1994:86:483-9.

152 Kawano M, Hirano T, Natsuda T, et al. Autocrine generation and requirement of BSF-2/IL-6 for human multiple myelomas. Nature 1988;332:83-5.

153 Miles SA, Rezai AR, Salazar-Gonzales JF, AIDS Kaposi's sarcoma-derived cells produce and respond to interleukin 6. Proc Natl Acad Sci U S A 1990;87:4068-72.

154 Zhang XG, Klein B, Bataille R. Interleukin-6 is a potent myeloma-cell growth factor in patients with aggressive multiple myeloma. Blood 1998;74:11-13.

155 Asou H, Said JW, Yang R, et al. Mechanisms of growth control of Kaposi's sarcoma-associated herpesvirusassociated primary effusion lymphoma. Blood 1998;91: 2475-81.

156 Jones $\mathrm{KD}$, Aoki Y, Chang $\mathrm{Y}$, et al. Involvement of interleukin-10 (IL-10) and viral IL-6 in the spontaneous growth of Kaposi's sarcoma herpesvirus-associated ingrowth of Kaposi's sarcoma herpesvirus-associated infected primary

157 Aoki Y, Jaffe ES, Chang Y, et al. Angiogenesis and hematopoiesis induced by Kaposi's sarcoma-associated herpesvirus-encoded interleukin-6. Blood 1999;93:403443.
158 Molden J, Chang Y, You Y, et al. A Kaposi's sarcomaassociated herpesvirus-encoded cytokine homolog (vIL-6) subunit. F Biol Chem 1997;272:19625-31.

159 Wan X, Wang H, Nicholas J. Human herpesvirus 8 interleukin-6 (vIL-6) signals through gp130 but has structural and receptor-binding properties distinct from those of human IL-6. F Virol 1999;73:8268-78.

160 Cannon JS, Nicholas J, Ornstein JM, et al. Heterogeneity of viral IL6 expression in HHV-8-associated disease. $\mathcal{F}$ Infect Dis 1999;180:824-8.

161 Staskus KA, Sun R, Miller G, et al. Cellular tropism and viral interleukin-6 expression distinguish human herpesvirus 8 involvement in Kaposi's sarcoma, primary effusion ymphoma, and multicentric Castleman's disease. F Virol 1999;73:4181-7.

162 Burysek L, Yeow W-S, Lubyova B, et al. Functional analysis of human herpesvirus 8-encoded viral interferon regulatory factor 1 and its association with cellular interferon regulatory factors and p300. F Virol 1999;73:7334-42.

163 Camarda G, Spinetti G, Bernardini G, et al. The equine herpesvirus $2 \mathrm{E} 1$ open reading frame encodes a functional chemokine receptor. 7 Virol 1999;73:9843-8.

164 Arvanitakis L, Yaseen N, Sharma S. Latent membrane protein-1 induces cyclin D2 expression, pRb hyperphosphorylation, and loss of TGF-beta 1-mediated growth nhibition in EBV-positive B cells. F Immunol 1995;155: 1047-56.

165 Birkenbach M, Josesen K, Yalamanchili R, et al. EpsteinBarr virus-induced genes: first lymphocyte-specific G protein-coupled peptide receptors. F Virol 1993;67:2209-20.

166 Sinclair AJ, Palmero I, Peters G, et al. EBNA-2 and EBNA-LP cooperate to cause G0 to G1 transition during immortalization of resting human B lymphocytes by Epstein-Barr virus. EMBO ₹ 1994;13:3321-8.

167 Cheng EH, Nicholas J, Bellows DS, et al. A Bcl-2 homolog encoded by Kaposi's sarcoma-associated virus, human herpesvirus 8 , inhibits apoptosis but does not heterodimerize with Bax or Bak. Proc Natl Acad Sci U S A 1997;94:690-4.

168 Nava VE, Cheng EH, Veliuona M, et al. Herpesvirus saimiri encodes a functional homolog of the human bcl-2 oncogene. F Virol 1997;71:4118-22.

169 Thome M, Schneider P, Hofmann K, et al. Viral FLICE-inhibitory proteins (FLIPs) prevent apoptosis induced by death receptors. Nature 1997;386:517-21.

170 Dittmer D, Lagunoff M, Renne R, et al. A cluster of latently expressed genes in Kaposi's sarcoma-associated herpesvirus. F Virol 1998;72:8309-15.

171 Jung JU, Stager M, Desrosiers, RC. Virus-encoded cyclin. Mol Cell Biol 1994;14:7235-44.

$172 \mathrm{Li} \mathrm{M}$, Lee $\mathrm{H}$, Yoon D-W, et al. Kaposi's sarcomaassociated herpesvirus encodes a functional cyclin. 7 Virol 1997;71:1984-91.

173 Nicholas J, Cameron KR, Honess RW. Herpesvirus saimiri encodes homologues of $\mathrm{G}$ protein-coupled receptors and cyclins. Nature 1992;355:362-5.

174 Swanton C, Mann OJ, Fleckenstein B, et al. Herpes viral/cdk6 complexes evade inhibition by cdk inhibitor proteins. Nature 1997;390:184-7.

175 Hoge AT, Hendrickson SB, Burns WB. MHV68 cyclin-D homologue is required for efficient reactivation from latency. f Virol 2000;74:7016-23.

176 Simas JP, Swann D, Bowden R, et al. Analysis of murine gammaherpesvirus-68 transcription during lytic and latent infection. F Gen Virol 1999;80:75-82. 